\title{
EL REFERÉNDUM FRANCÉS DE RATIFICACIÓN DEL TRATA- DO QUE ESTABLECE UNA CONSTITUCIÓN PARA EUROPA, DE 29 DE MAYO DE 2005
}

\author{
POR \\ ISABEL M. ${ }^{a}$ CANTOS PADILLA \\ Profesor Titular de Derecho Constitucional \\ de la Universidad Autónoma de Madrid
}

\section{INTRODUCCIÓN}

Este estudio tiene como objetivo estudiar el referéndum celebrado recientemente en Francia para aprobar el Tratado que establece una Constitución para Europa. La victoria del "no" en esta consulta, así como en la celebrada en Holanda dos días después, ha abierto una crisis en la Unión Europea sólo comparable con la que se produjo hace cincuenta años cuando Francia dio su negativa a la CED (Comunidad Europea de Defensa), negativa cuyas consecuencias duraron varias décadas ${ }^{1}$. Además,

1 El embrión de la Unión Europea sobrevivirá gracias a la firma en Roma, en 1957, de los tratados que institucionalizaron el EURATOM y el Mercado Común. Estos tratados serían ratificados, no sin dificultad, por los seis países fundadores de lo que actualmente Ilamamos la UE. 
plantea muchos interrogantes sobre la viabilidad de una verdadera unión federal entre los veinticinco Estados que ahora conforman la Unión y deja en el aire la futura incorporación de otros - como Rumanía y Bulgaria-, a la vez que descarta de momento la entrada de Turquía, incluso a largo plazo, como miembro de pleno derecho. Las primeras reacciones a este doble rechazo por parte del resto de países que aún no habían ratificado el Tratado han consistido en suspender la consulta (Gran Bretaña) para una posible aprobación parlamentaria, o en aplazar el referéndum programado (Polonia, Dinamarca y República Checa). Finalmente ha sido la Comisión la que ha zanjado el asunto, aplazando sine die las ratificaciones, para evitar otras medidas unilaterales del resto de países miembros.

Dado que el objetivo de este artículo es centrarse en la experiencia francesa, sirva el párrafo anterior de mera introducción, aunque, evidentemente, dado el tema de la consulta, se han hecho referencias a Europa donde se ha creído necesario. Se ha incluido, en primer lugar, un apartado para ilustrar la mecánica del referéndum y de la reforma constitucional.

\section{BREVE INCISO SOBRE EL REFERÉNDUM Y LA REVISIÓN CONSTITUCIONAL EN EL RÉGIMEN FRANCÉS DE LA V REPÚBLICA}

La aprobación de la Constitución para Europa ha requerido la correspondiente reforma constitucional que después se ha sometido a referéndum. Hay que subrayar que esta consulta popular -así como la de 2000, por la que se aprobó el quinquenato- ha sido sólo el último eslabón —el de la ratificación (art. 89.2) ${ }^{2}$ — de la reforma constitucional previa, necesaria para acomodar a la Constitución el compromiso internacional que el Tratado implica, y no un referéndum legislativo (previsto en el artículo $11^{3}$ ), por cierto, indebidamente utilizado a comienzos

2 Según el apartado 2 del artículo 89, inciso final, la reforma será definitiva después de ser aprobada por referéndum.

3 Artículo 11: El Presidente de la República, a propuesta del Gobierno, y mientras dure el período de sesiones, o a propuesta conjunta de las dos Asambleas, publicadas en el Diario Oficial, puede someter a referéndum cualquier proyecto de ley relativo a la organización de los poderes públicos, sobre las reformas relativas a la política económica y social de la Nación y a los servicios públicos que concurren en ella, o que tiendan a autorizar la ratificación de un tratado que, sin ser contrario a la Constitución, incidiere en el funcionamiento de las instituciones.

Cuando se organice el referéndum a propuesta del Gobierno, éste presentará, ante cada Asamblea, una declaración que será seguida de debate. 
de la $\vee$ República para reformas constitucionales ${ }^{4}$. Ejemplos de ella fueron los referendos de 1962 y $1969^{5}$. Desde el punto de vista jurídico

Cuando el referéndum sea favorable a la adopción del proyecto, el Presidente de la República lo promulgará en los quince días siguientes a la proclamación de los resultados de la consulta.

${ }^{4}$ El referéndum legislativo es una de las funciones presidenciales exentas de refrendo que mayor controversia ha suscitado, por dos motivos: en primer lugar por el uso impropio que se ha hecho de él durante los períodos en los que mayoría presidencial y parlamentaria han coincidido, aprovechando la aparente vaguedad del concepto de poderes públicos $\mathrm{y}$, en segundo lugar y fundamentalmente, por haberse utilizado sesgadamente, según hemos dicho, como vía para la reforma constitucional. Desde el punto de vista jurídico, una de las principales razones de esta indebida utilización del artículo 11 ha sido, en efecto, que el recurso directo a la voluntad popular permite salvar los obstáculos que rodean el procedimiento del artículo 89 -aprobación por las dos asambleas en términos idénticos y exigencia del refrendo ministerial- y que, además, tiene la ventaja de gozar de la legitimidad que otorga la aprobación directa del electorado, voluntad soberana por excelencia que subsana - hay que reconocerlo- la incorrecta utilización del art. 11 y ante la cual no cabe recurso de inconstitucionalidad, como reiteradamente lo ha manifestado el Tribunal Constitucional (cfr. Decisión n. ${ }^{\circ}$ 62-20 DC, 6 de noviembre de 1962, confirmada por la decisión n. ${ }^{\circ}$ 92-313 DC, de 23 de septiembre de 1992). En las dos decisiones emitidas sobre este particular, el Consejo constitucional confirma su vocación de órgano regulador de la actividad de los poderes públicos y se declara incompetente para decidir sobre leyes que constituyen la expresión directa de la soberanía nacional (cfr. Renoux, T. S. y de VilLiers, M., op. cit., p.11). Finalmente sostenemos que, si alguna institución tiene la capacidad de interpretar la Constitución, esa es el Consejo Constitucional, a quien corresponde pronunciarse sobre cuestiones de constitucionalidad, tarea que implica una labor de interpretación del texto.

El referéndum legislativo, como su mismo apelativo indica, se aplica exclusivamente a proyectos de ley (ordinaria u orgánica) y el tema sometido a consulta popular debe versar sobre tres dominios estrictamente limitados: la organización de los poderes públicos, las reformas relativas a la política económica o social de la nación y a los servicios públicos que concurran en ellas o, por último, ir destinado a autorizar la ratificación de un tratado que, sin ser contrario a la Constitución, tendría incidencias en el funcionamiento de las instituciones. La decisión presidencial de recurrir al referéndum adopta la forma de real decreto.

Desde el punto de vista político, los inspiradores de la Constitución (de Gaulle o Debré) concibieron el recurso al referéndum como un sustituto de la disolución, es decir como un recurso arbitral (y por lo tanto en conexión con el artículo 5) en el caso de retirada de confianza al Gobierno por parte de la Asamblea Nacional, lo que permite apelar directamente al electorado cuando existe un conflicto de decisión entre las distintas instituciones implicadas. Sin embargo, para De Gaulle era algo más: era una forma de revalidar la confianza del electorado hacia la institución presidencial. Precisamente esta concepción, en la que basó el referéndum de 1969, lo condujo irremediablemente a la dimisión (cfr. AvRIL, Pierre, La Ve République. Histoire politique et constituonnelle, op. cit., p. 155 y ss). En cambio, para algunos constitucionalistas presidencialistas como René Capitant, la ventaja fundamental del referéndum legislativo radica en lo que tiene de democracia directa o de consulta popular (cfr. ConAC, Gérard, op. cit.., p. 415).

(c) UNED. Revista de Derecho Político

N. ${ }^{\circ} 65-2006$ 
lo reprochable de esta sesgada aplicación del artículo 11 radica en la derogación que realiza del procedimiento legislativo común establecido, pues implica una invasión del Poder ejecutivo en el legislativo.

En realidad, la exégesis de los artículos 11 y 89 (dedicados, respectivamente, al referéndum legislativo y a la reforma constitucional) no deja lugar a dudas: la organización de los poderes públicos (ámbito de aplicación del artículo 11) constituye un dominio distinto y bien delimitado de los poderes públicos constitucionales, cuya revisión es objeto específico del procedimiento previsto en el artículo $89^{6}$. La misma redacción del apartado primero del artículo 11, que excluye la utiliza-

5 El primero versó sobre el cambio en el modelo de elección presidencial, que tras el respaldo popular pasó a ser directa, lo que en la práctica aumentó la legitimidad presidencial y fortaleció la institución, pero también fue el punto de partida para una práctica presidencialista en la $V$ República, pues se combinó con un largo período de coincidencia de mayorías (presidencial y parlamentaria). Esta situación cambiaría, en 1986, con la primera cohabitación o diarquía. El segundo, el de 1969, versaba sobre la creación de las regiones y sobre la reforma del Senado, que reducía éste a un mero órgano consultivo. La reforma no obtuvo el respaldo popular necesario y forzó, como hemos dicho, la dimisión de de Gaulle, que públicamente siempre había comprometió su responsabilidad al resultado de los referendos. En contrapartida, el Senado salió fortalecido. Sin embargo el fondo político-jurídico de ambas consultas fue el mismo: bloquear la acción del Parlamento en esas reformas.

6 Michel Troper ha sostenido, sin embargo, que el Presidente tiene un monopolio de interpretación constitucional que le habilita a determinar el alcance de la expresión "poderes públicos" (cit. por CONAC, Gerad, "Le Président de la République", art. 11, p. 441). Pensamos con ConAC que el problema es más político que jurídico, es decir, si ha prevalecido la opinión del Presidente es porque el pueblo, árbitro supremo, se ha pronunciado a su favor, respondiendo positivamente a la cuestión planteada (indem, id. ibid.). En efecto, en nuestra opinión, la Constitución no habilita al Presidente a interpretar la Constitución. Esa suposición, que sólo puede encontrar apoyo en la función de guardián de la Constitución que consagra el artículo 5, no tiene sostén jurídico si se considera, tesis que creemos la más acertada, que este artículo no es una cláusula de habilitación general sino un enunciado de las funciones presidenciales que luego se van concretando en el resto del articulado, pues el mismo artículo no habilita los medios para llevar a cabo las funciones que anuncia. Coincidimos con Philipe ARDANT en que el Presidente tiene a su cargo un cierto número de intereses taxativamente enumerados y se limita a defenderlos, por lo que el término que mejor definiría su función sería el de tutor. La elección presidencial por sufragio universal directo, si bien fortalece la legitimidad presidencial, no transforma su función, porque no modifica la lista de poderes presidenciales. El Presidente ejerce además competencias debidas, dado que no puede renunciar a las misiones que la Constitución le confía. No puede permanecer pasivo llegado el momento que determina su intervención; a lo sumo puede elegir, en determinados casos, el procedimiento más oportuno (cfr. "L'article 5 et la fonction présidentielle», op. cit., pp. 47 a 50). 
ción del procedimiento referendario con vistas a la ratificación de tratados contrarios a la Constitución, no hace sino confirmar esta interpretación $n^{7}$.

Centrándonos en la reforma constitucional que nos ocupa, puesta en práctica por la vía ortodoxa del artículo 89, cabe preguntarse sobre las razones de haber seguido esta forma de ratificación, cuando el artículo 89.3 de la Constitución francesa permite que el Presidente someta la reforma al Parlamento convocado en Congreso, en lugar de a la consulta popular, vía prevista, en principio, como ordinaria ${ }^{8}$. Decimos "en principio" porque ésta es sólo la segunda vez en la historia de la $V$ República que una reforma constitucional es sometida a la ratificación por referéndum. Hasta entonces todas las reformas constitucionales se ratificaron por la vía parlamentaria, que es en realidad la vía que la letra del apartado segundo del artículo 89 prevé como alternativa.

Esbozando someramente el esquema constitucional del texto de 1958 previsto para la revisión, conviene apuntar que las vías que prevé el artículo 89 son tres, a saber: iniciativa presidencial —asambleas-referéndum, iniciativa presidencial —asambleas-congreso e iniciativa parlamentaria —asambleas - referéndum. La iniciativa presidencial requiere la propuesta previa del Gobierno. La iniciativa parlamentaria, por su parte, tiene la ventaja de sustraerse al requisito de fijación en el orden del día ${ }^{9}$. Como hemos dicho, la aprobación por ambas asambleas es en términos idénticos, por lo que el Senado puede suponer un obstáculo importante para la aprobación parlamentaria cuando el Ejecutivo

7 El artículo 11 experimentó una revisión en 1995 que amplió su campo de aplicación, medida que, más que suprimir, creó nuevas ambigüedades, a saber: qué debe entenderse concretamente por reformas relativas a la política económica o social de la nación y a los servicios públicos. Esta ampliación del campo de aplicación del referéndum y la indeterminación del artículo que comentamos corre el peligro de desembocar en una laxitud interpretativa que haga de las materias objeto del procedimiento referendario una cláusula general de competencia. Por el contrario, una interpretación demasiado restrictiva podría hacer del referéndum una reliquia constitucional.

8 No obstante, el proyecto de reforma no será sometido a referéndum cuando el Presidente de la República decida someterlo al Parlamento convocado en Congreso; en este caso el proyecto de reforma será aprobado, solamente, si obtiene una mayoría de los tres quintos de los votos emitidos. La Mesa del Congreso será la de la Asamblea Nacional (traducción recogida de AlVAREZ VÉLEZ, M. ${ }^{a}$ Isabel y ALCON YUSTAS, M. ${ }^{a}$ Fuencisla, Las Constituciones de los Quince Estados de la Unión Europea, Madrid), 1996).

9 Cfr. Villiers, Michel y Renoux, Thierry S., Code constitutionnel commenté et annoté, op. cit., p.681. 
está en el origen de la revisión, a diferencia de lo que ocurre en el procedimiento legislativo ordinario, en el que éste dispone de mecanismos para imponerse a la Asamblea ${ }^{10}$. La doctrina coincide en afirmar que, una vez aprobado el proyecto de revisión por las cámaras, el Presidente debe seguir con el procedimiento, por cualquiera de las dos vías previstas, y que no puede, en buena lógica constitucional, oponerse a la voluntad del Parlamento quedando inactivo. Asimismo las dos vías de ratificación, la parlamentaria y la referendaria, son exclu-

10 El efecto, la Constitución de 1958 arbitra una serie de mecanismos que permite que el Gobierno se imponga al Parlamento. El conjunto de los mismos se ha dado en llamar parlamentarismo racionalizado. Este, siguiendo a los profesores Fernández-Miranda, no es sino el trasunto continental del parlamentarismo inglés, corregido para contrarrestar los inconvenientes del multipardismo y la frecuente carencia de mayorías estables en la asamblea, que dificultan la tarea de Gobierno (cfr. FERnÁNDEZ-MiRANDA CAMPOAMOR, Carmen y Alfonso. Sistema electoral, partidos políticos y Parlamento, Madrid, Constitución y Leyes S.A. (COLEX), 2003, pp. 197 y ss.). En el caso concreto francés, junto a las medidas más contundentes desde el punto de vista activo o de impulsión política del art. 49.3 consistentes en la posibilidad de que el Primer Ministro comprometa su responsabilidad sobre un texto (el texto se considera aprobado si en veinticuatro horas no se ha planteado la moción de censura) y del art. 49.4, en virtud de la cual el Primer Ministro puede pedir al Senado la aprobación de una declaración de política general, existen otras como el voto bloqueado (art. 44.3), por el que se solicita de la Asamblea que se pronuncie mediante un solo voto sobre todo o parte del texto en discusión y no teniendo en cuenta más que las enmiendas propuestas o aceptadas por el Gobierno, la prioridad en la discusión del orden del día (art. 48), la capacidad de convocar a la Comisión Mixta Paritaria en el caso de que las dos Asambleas no estén de acuerdo o si el Gobierno declara la urgencia (art. 45.2), la facultad de pedir a la Asamblea que decida definitivamente, tras una nueva lectura del proyecto de ley en la Asamblea y el Senado (art. 45.4) o de convocar al Senado en el caso de que la Asamblea Nacional no se pronuncie en el plazo de cuarenta días - el Senado dispone de quince días para decidir-, la capacidad de poner en vigor las leyes por medio de ordenanzas en el caso de que el Parlamento no se haya pronunciado en sesenta días (art. 47), de solicitar del Parlamento autorización para adoptar, por medio de ordenanzas, medidas que entran dentro del dominio de la ley (art. 38) o la facultad de decidir que se celebren días suplementarios de sesión (art. 28.3). Desde el punto de vista defensivo, el Gobierno dispone además de medidas para cortocircuitar, si lo desea, la acción del Parlamento, como, por ejemplo, la capacidad de ejercer - compartida con el Parlamento- el derecho de enmienda (art. 44.1) o de controlar en cierto modo las proposiciones de ley y las enmiendas del parlamento (art. 41) consistente en poder rechazar un texto que no entre dentro del dominio de la ley o que sea contrario a una delegación concedida en virtud del art. 38, el no aceptar ninguna enmienda sin el acuerdo del Gobierno (art. 45) o, en fin, el hecho de disponer de la gran mayoría de los días de sesión para la discusión de sus proyectos, en comparación con el Parlamento, que goza tan sólo de una sesión por semana (art. 48). 
yentes entre sí, de modo que una vez rechazado el proyecto de revisión por el Parlamento, éste no puede ser sometido a aprobación en referéndum, es decir, el pueblo no es una especie de jurisdicción de segunda instancia, en caso de rechazo parlamentario ${ }^{11}$. Tampoco el Consejo Constitucional puede imponerse al poder constituyente y su actuación, en estos supuestos, es meramente marginal, es decir, no puede excluirse su convocatoria en el caso de una ley de revisión aprobada en Parlamento, pero es nula en todos los casos de ratificación por referéndum, al igual que es nula - ya se ha apuntado- en los casos de revisión indebidamente llevada a cabo por el procedimiento del artículo 11, pues la voluntad del pueblo, expresada directamente, es soberana. Sin embargo, desde el punto de vista de la jerarquía de las normas, una disposición introducida en la Constitución por la vía del referéndum del artículo 11 y que sea materialmente constitucional puede ser modificada por una revisión llevada a cabo siguiendo el procedimiento del artículo $89^{12}$, se entiende que siguiendo cualquiera de las modalidades previstas en el mismo.

Si nos detenemos en la utilización que los presidentes de la $\mathrm{V}$ República han hecho de las dos formas de ratificación del apartado tercero, surge la pregunta de por qué en estas revisiones constitucionales realizadas de forma ortodoxa, es decir, al amparo de este artículo, los presidentes franceses han excluido sistemáticamente la posibilidad de someter el proyecto de revisión a referéndum, haciendo un uso repetido de la prerrogativa que les concede el citado apartado, mientras que en otros casos las reformas constitucionales se han hecho contra legem utilizando precisamente el artículo 11 dedicado al referéndum. La explicación de esta aparente falta de coherencia estriba en que el referéndum (por lo demás obligatorio en la vía parlamentaria) es precisamente un arma del Presidente para imponerse al Parlamento, solicitando directamente la opinión del electorado, cuando el Jefe del Estado está en contra de la revisión ${ }^{13}$. En cambio, cuando el ejecutivo está en el origen de la re-

11 Sobre este aspecto véase VILLIERS, Michel y Renoux, Thierry S. (Code constitutionnel commenté et annoté, op. cit., p. 683).

12 Idem, id. Ibid.

13 Según CoHENDET, Anne-Marie, los redactores de la Constitución previeron el referendum para el supuesto de hostilidad presidencial a la revisión en su iniciativa parlamentaria. De ese modo el pueblo tenía la oportunidad de dirimir el desacuerdo mediante su arbitraje (cfr. La cohabitation, leçons d'une expérience, op. cit., p. 212). Asimismo, según Philippe ARDANT, cuando la revisión se realiza por la vía del artículo 89, el referéndum se justifica en el caso de inciativa parlamentaria, para evitar excluir al Ejecutivo del procedimiento. (cfr. Les institutions de la Ve République, op. cit. pp. 22 y ss.).

(C) UNED. Revista de Derecho Político 
visión y tiene apoyo en las asambleas no hay razón para someter el proyecto al pesado procedimiento del referéndum, sobre todo si se trata de simples modificaciones técnicas o de detalle ${ }^{14}$.

Ambas vías de ratificación, la parlamentaria y la referendaria requieren un acto positivo del Jefe del Estado, un decreto refrendado ${ }^{15}$. En efecto, esta facultad presidencial del artículo 89.3 no está incluida en el artículo 19 entre los actos presidenciales exentos de refrendo. Políticamente, dado el momento de mayorías afines que atraviesa el régimen francés, la exigencia de refrendo es irrelevante dado que la decisión corresponde al Jefe del Estado, aunque la responsabilidad se traslade al ministro refrendante, es decir, no hay traslado de competencia, pero sí de responsabilidad y al ministro que no quiera asumir ésta sólo le queda la dimisión ${ }^{16}$. En cambio, en período de cohabitación, el Jefe de Estado debe asegurarse previamente que cuenta con el acuerdo del Gobierno. Sin embargo, el caso de la opción que abre el apartado tercero del artículo 89 merece una especial consideración. EI texto dice que, una vez iniciado el proyecto de reforma constitucional (es decir, tras ser votado por ambas cámaras), el Presidente puede "decidir» -éste es el verbo utilizado- someter su aprobación definitiva al Parlamento convocado al efecto en Congreso. La redacción de este apartado ha llevado a muchos a sostener que esta capacidad de decisión presidencial existe siempre, incluso en cohabitación ${ }^{17}$. A nuestro juicio, en la mecánica del refrendo no caben excepciones, por lo que, en período de cohabitación, en el que la práctica política funciona más acorde con el texto constitucional, debe entenderse que toda decisión presidencial lleva implícita una deliberación previa de las instituciones implicadas, así como la existencia de un acto conjunto (el presidencial), fruto de una decisión por ellas compartida, donde a me-

14 Cfr. Idem, id., ibid.

15 Este refrendo lo realiza el ministro encargado de defender el proyecto, que no es necesariamente el Primer Ministro (cfr. de Villiers, Michel y Renoux, Thierry S., Code constitutionnel commenté et annoté, op. cit., p. 680).

${ }^{16}$ Así fue como dimitió Jean-Pierre Chevènement, por negarse a firmar cualquier decisión — siendo Primer ministro Jospin-que implicara la transferencia de competencias a la isla de Córcega.

17 En este sentido véase AuVRET, Patrick, "La Faculté d'empêcher du Président de la République» en Revue du droit public et de la science politique, París, Librairie Générale de droit et de jurisprudence, 1986, vol. 1, pp. 160 y 161. Para este autor, el refrendo ministerial no tiene por qué ser fruto de un poder discrecional. En su opinión, en el caso de la revisión constitucional el Presidente es el único maestro de la decisión de someter el proyecto, bien a referéndum, bien al Congreso y el refrendo no se le puede negar, salvo por un motivo de derecho. 
nudo es difícil determinar el origen real de la decisión ${ }^{18}$. Sin embargo, hay que admitir que en la práctica, dada la expresa referencia constitucional a la capacidad del Presidente de decidir en este caso sobre un procedimiento $u$ otro, es muy poco probable que un ministro niegue el refrendo a esta decisión, incluso en cohabitación, lo que nos lleva una vez más a la tesis apuntada, a que cualquier acto presidencial refrendado se elabora dentro del Ejecutivo y que detrás de este acto cabe un diálogo, que no por ser mucho menos fluido en período de cohabitación, debe de excluirse de antemano.

\section{ANTECEDENTES DE LA CAMPAÑA DEL REFERÉNDUM DEL 29 DE MAYO}

Para valorar adecuadamente las circunstancias que han rodeado el referéndum francés de ratificación del Tratado sobre la Unión Europea es preciso remontarse a las elecciones legislativas y presidenciales de 2002. El resultado de aquella doble consulta electoral y las circunstancias que la rodearon obligaron al electorado a volver a votar a Jacques Chirac - que accedió por primera vez a la presidencia en 1995como mal menor, para alejar el fantasma de la ultraderecha, así como a ratificar posteriormente esa decisión en las elecciones legislativas que se celebrarían a continuación, para evitar que volviera a repetirse el fenómeno de la cohabitación ${ }^{19}$. Los resultados de aquellos comicios pueden considerarse un primer indicativo de la negativa que ahora el mismo electorado ha dado al Tratado sobre la Constitución Europea. Entonces el descontento del electorado se tradujo, por una parte, en la eliminación, ya en la primera vuelta de la elección presidencial, del líder socialista en el gobierno, Lionel Jospin, que valorando inadecuadamente el alcance del saldo negativo con el que había partido en las elec-

18 Nos sumamos por lo tanto a la opinión de GAXIE, Daniel, para quién el refrendo presupone siempre un acuerdo en el seno del ejecutivo (cfr. "Titre XIV. De la révision. Article 89", en VV.AA., La Constitution de la République Française, op. cit., p. 1332). Este refrendo lo realiza el ministro encargado de defender el proyecto, que no es necesariamente el Primer Ministro (cfr. de Villiers, Michel y Renoux, ThierRY, S., Code constitutionnel commenté et annoté, op. cit., p.680).

19 Recordemos que el objetivo de impedir una situación de antagonismo entre la Asamblea Nacional y la Presidencia de la República había sido una de las causas de la reforma de la institución presidencial que redujo el mandato del Jefe del Estado de siete a cinco años mediante el referéndum celebrado en septiembre de 2000 . Esta medida se completaría, en víspera de la doble consulta electoral de 2002 a la que nos estamos refiriendo, con la inversión del calendario electoral. 
ciones municipales de 2001, propuso la inversión del calendario electoral, anteponiendo las elecciones presidenciales a las legislativas (éstas, con la reducción del mandato presidencial a cinco años, habían quedado situadas justo un poco antes de aquellas) ${ }^{20} \mathrm{y}$, por otra, el significativo auge del ultraderechista Le Pen, que se quedó a solas frente a Chirac en la segunda vuelta. En efecto, el malestar de una parte significativa del electorado con la política seguida por la mayoría gobernante hasta las citadas elecciones y el hecho de que en la misma se enarbolaran ciertos temas de gran repercusión social, como el de la seguridad ciudadana ${ }^{21}$, seguido a larga distancia de otros, como el desempleo, favoreció en las presidenciales el auge del Partido Nacional, que, por su escasa estructura, es un partido que se desenvuelve mejor en este tipo de comicios, a la vez que cuenta con un electorado organizado y poco absentista.

La tormenta electoral francesa de 2002 se resolvió, paradójicamente, del modo más tradicional conocido en la historia de la $\mathrm{V}$ República: Chirac se convirtió, siguiendo la lógica presidencialista iniciada en 1958, en Presidente de hecho y de derecho. Los resultados lo hicieron vencedor absoluto de los comicios. Había conseguido obligar incluso a la izquierda a rendirle su voto, por el miedo a que el Frente Nacional se convirtiera en lo sucesivo en árbitro de los comicios nacionales. El electorado francés se vio así constreñido a dar un voto útil a Chirac, que había iniciado la campaña muy desgastado tras siete años en el Elíseo, en los que los repetidos escándalos de corrupción se habían alternado con una política liberal, si bien debe hacerse mención aparte del período de cohabitación 1997-2002 -la tercera, iniciada tras las legislativas de $1997^{22}$ - en la que la puesta en practica de una política de centro-iz-

${ }^{20}$ Los bien fundados argumentos que el entonces partido gobernante (desde la cohabitación que se inició en 1997), adujo para fundamentar esta inversión, a saber, que de ese modo se hacía de la elección presidencial el momento fuerte de la vida política y se evitaba que un Primer Ministro pudiera ser nombrado por un Presidente cuyo mandato estaba a punto de expirar, no lograban ocultar, sin embargo, las verdaderas intenciones meramente electoralistas del PS, que eran en realidad el sacar ventaja del desgaste político de Chirac como presidente y ganar las presidenciales, lo que le facilitaría su victoria en las legislativas. La opción contraría, en cambio, podía dejarle fuera de ambas elecciones si se cumplía la regla del castigo al partido de la mayoría.

21 Esta campaña contra la inseguridad, iniciada por Chirac el 14 de julio de 2001, sirvió en efecto para nutrir el electorado del Frente Nacional, que convirtió la inseguridad ciudadana en el centro de su política.

22 Como es sabido, la disolución de la Asamblea Nacional en 1997 por Jacques Chirac para adecuar la mayoría presidencial a la parlamentaria, en lugar de acabar con la cohabitación existente, creó una nueva. 
quierda por parte del PS, tampoco supo satisfacer a la mayor parte del electorado. Reelegido presidente, la victoria de la UMP -que aglutinó a las fuerzas de derecha y de centro-derecha- en las legislativas le permitieron nombrar a Raffarin ${ }^{23}$, un mandatario de confianza, pero también un representante de la derecha con baja sensibilidad, al frente del Gobierno, en lugar de nombrar a un candidato de centro. Como mensaje a la nación posterior a su doble victoria electoral $^{24}$, Chirac declaró haber entendido la lección que los franceses le habían querido impartir, si bien, acto seguido, hizo todo lo contrario de lo anunciado: desplegó una política de claro corte liberal, opuesta a la prometida ${ }^{25}$.

La desatención de Chirac del grito ciudadano expresado en los comicios de 2002, motivó un fortísimo rechazo del electorado a la UMP en las elecciones regionales de 2004, en las que quedó muy por debajo del Partido Socialista. Por segunda vez desde su reelección declaró haber entendido el mensaje de la nación $y$, si bien no pudo decir, como en 2002, que "el voto obliga", no pareció sentirse más condicionado que en escrutinios anteriores, como ilustra, por ejemplo, el hecho de que no sustituyera a su jefe de gobierno.

Tras los antecedentes expuestos, en este referéndum de 2005 sobre la Constitución Europea el electorado francés ha venido arrastrando un sentimiento de desconfianza, desencanto y malestar que, lejos de encontrar respuesta política, se ha visto agravado por la persistencia de

23 Desde el punto de vista institucional se atribuye a Raffarin el haber sido el teórico del quinquenato y haber sabido conciliar la derecha orleanista de d'Estaing y la bonapartista de Chirac. Su labor más importante en el seno de la UMP es la de haber conseguido unir a los seguidores de ambos, divididos desde 1976.

24 En efecto, tras el seísmo de las dobles elecciones de 2002, Chirac asumió el compromiso solemne de tener en cuenta el veredicto del Pueblo (cfr. Le Monde, 0605-2005, p. 1).

25 En realidad Chirac se limitará a cumplir con buena parte con las promesas electorales, pero sin tener en cuenta las circunstancias que motivaron su reelección. Entre las medidas llevadas a cabo por Raffarin figuran la bajada del impuesto sobre la renta, la reforma sobre la financiación de las jubilaciones y de la seguridad social (ampliación a cuarenta y un años de las cotizaciones para tener derecho a una pensión completa de jubilación), y la concesión a las empresas de facilidades en las cotizaciones sociales patronales. Sin embargo la parte más emblemática de su gestión la componen sus medidas sobre descentralización (muchas competencias se encuentran ya transferidas a las colectividades territoriales). Pese a todo, su gestión al frente del gobierno le granjeará impopularidad y ha sido calificada de liberal, pues las medidas puestas en práctica favorecen, sobre todo, a las clases más acomodadas. Sin embargo, lo que más se le reprocha es no haber conseguido bajar la tasa del desempleo, que tras la consulta superará el $10 \%$. 
los problemas sociales, consistentes básicamente en un fuerte desempleo, superior al $10 \%$, así como estancamiento de los salarios y del crecimiento económico. A ello hay que sumar los problemas inherentes a las posibles implicaciones del Tratado en la economía nacional, a saber, el miedo a que la nueva Constitución favorezca la fuga de empresas en busca de mano de obra barata procedente del Este, el fantasma del aún lejano, pero no imposible a largo plazo, ingreso de Turquía en la Unión o la misma Constitución Europea, que, fruto, como es sabido, de un difícil consenso entre sus miembros, no responde plenamente ni a las demandas sociales de la izquierda clásica ni a las ansias la derecha más liberal, que desean ver Europa convertida en una superpotencia económica. Hay que apuntar, además, que el voto por Europa, pese a sus ventajas evidentes, supone un compromiso cuyas implicaciones a medio y largo plazo están por determinar, mientras que el "no" ha sido visto por muchos votantes como un impass que permitirá una renegociación y una retoma de posiciones. Al menos ésta parece ser la opinión del electorado manifestada en las encuestas que, a la vista del resultado de esta consulta y como se ha apreciado de forma bastante clara durante la campaña, ha estado bastante alejado de sus mandatarios en el Parlamento.

En conclusión, a nuestro juicio, los problemas descritos, sumados a la utilización, no exenta de intereses electoralistas, que los políticos detractores del Tratado han hecho de ellos, ha convertido esta consulta en una cuestión de política interna más que en un debate sobre Europa y, el referéndum mismo, en una especie de comicios nacionales. El "no" francés al Tratado es, por lo tanto, un «no» grande y rotundo a la política de Chirac.

\section{CAMPAÑA PREVIA AL REFERÉNDUM DE RATIFICACIÓN}

\subsection{Inicio de la campaña}

Más adelante nos referiremos a las posibles razones de Chirac para no hacer uso de la facultad que le confiere el artículo 89.3, lo que le habría ahorrado este fracaso político.

Tras el sobrado apoyo parlamentario a la Constitución Europea el lunes 28 de febrero, los resultados se hacen públicos 1 de marzo ${ }^{26}$. La

${ }^{26}$ En efecto, 730 diputados y senadores dieron luz verde al proyecto, frente a 66 diputados y senadores que votaron en contra y 96 diputados y senadores que se abstuvieron de la votación (cfr. Le Monde, 2 de marzo de 2005, p. 1). En estos pri- 
aprobación se consigue gracias al apoyo del Partido Socialista y de los Verdes. El 6 de marzo, en el seno de la UMP, los 2500 cuadros de la UMP aprueban, con un porcentaje del $90,8 \%$, un texto proponiendo un "sí franco y masivo" a la Constitución Europea y rechazando la adhesión de Turquía. Se marginan las voces discordantes. En este momento se desestima el valor del "no" pues los primeros sondeos realizados auguran una victoria del "sí» en el $63 \%$ de los encuestados ${ }^{27}$, si bien la mayoría gobernante reconoce ya que existen puntos negativos, que son son, aparte del asunto Gaymard ${ }^{28}$, el tema de Turquía y la movilización de los estudiantes ${ }^{29}, y$, concretamente en el terreno de la economía nacional, el bajo crecimiento económico ${ }^{30}$ y la persistencia de la elevada tasa de desempleo ${ }^{31}$, que se teme pueda aumentar en la Europa de los veinticinco por la potencial fuga de empresas. Esta posibilidad convertirá a las deslocalizaciones en el tema más debatido en la campaña. La polémica directiva Bolkestein sobre liberalización de servicios vendrá a crispar más los ánimos en materia social ${ }^{32}$.

meros días siguientes a la aprobación parlamentaria se invita a la Asamblea Nacional al dirigente español Rodríguez Zapatero, que interpelado sobre cuáles son, a su juicio, los avances más importantes de la Constitución Europea, responde que éstos son "paz, libertad, modelo social de economía de mercado y potencia en el mundo" (cfr. Le Monde, 3 de marzo de 2005).

27 Sondeo CSA para Francia Europa Press/Francia - Info (cfr. Le Monde, 2 de marzo de 2005, p. 1).

${ }_{28}$ Como consecuencia de este escándalo de corrupción, Gaymard, ministro de economía, dimite y es sustituído por Thierry Breton (cfr. Le Monde, 28 de febrero de 2005, p. 6)

29 Estos protestan, entre otras causas por el proyecto de ley que ha presentado el ministro de educación, conocida como "ley Fillon». En plena campaña referendaria esta ley será objeto de advertencia por el Consejo Constitucional, que da su visto bueno pero tras amputarle toda la parte III, la más polémica y simbólica, donde se precisaban los objetivos y medios del Gobierno en materia de educación (cfr. Le Monde 25-25 de abril de 2005, p. 1).

30 El índice medio de crecimiento es bajo en la zona euro. La media la mantienen Gran Bretaña y los países del Este, que registran los índices más altos. Las causas, según la UE, son la subida de precios del petróleo y la reafirmación del euro (cfr. Le Monde, 6 de abril de 2005, p. 8).

31 El desempleo rebasó la última semana de febrero la barrera del 10\%, por primera vez en cinco años, mientras que Raffarin se había comprometido a bajarla al $9 \%$. En otro país de la Unión, Alemania, también se registra un $12,6 \%$ de desempleo, el índice más alto después de la guerra (cfr. Le Monde, 2 de marzo de 2005, p. 8 y Le Monde, 3 de marzo de 2005, p. 6).

32 Aunque el Consejo Europeo de 22 y 23 de marzo decidirá no adoptarla tal y como fue redactada, inicialmente causa un gran impacto en políticos y ciudadanos, no sólo de Francia, sino también de Bélgica, Alemania y Suecia (cfr. Le Monde, 9 de abril de 2005, p. 1). 
Al ambiente social descrito arriba hay que sumar el éxito de la jornada de huelgas y manifestaciones organizada el 10 de marzo por los sindicatos para los asalariados, el empleo y la jornada de treinta y cinco horas ${ }^{33}$.

La misma semana de la aprobación parlamentaria, el viernes 4 , el Elíseo fija la fecha del referéndum para el 29 de mayo. Públicamente se opta por una campaña larga, pero se hace énfasis en la necesidad de que sea informativa y didáctica para disipar el mayor número posible de dudas ${ }^{34}$.

Los expertos señalan que cualquier movilización puede hacer subir el índice de votos negativos ${ }^{35}$. Raffarin, aconsejando a Bruselas, sostiene que hay que evitar las expresiones que creen miedo en el electorado $^{36}$. Paralelamente se descarta la venida de comisarios europeos a apoyar la campaña (Chirac ha criticado en numerosas ocasiones el modelo ultraliberal y atlantista de Gran Bretaña y se teme que su presencia en la campaña estimule el rechazo al Tratado por parte de aquellos que desean una Constitución más social).

Chirac entra formalmente en campaña con gran seguridad, anunciando públicamente su compromiso con el resultado porque, según él mismo declara, la suerte del escrutinio será definitiva para su quinquenato ${ }^{37}$. El 6 de marzo el partido de la mayoría (que aglutina a la UMP y a la UDF) lanza su eslogan: "Europa merece que se le diga

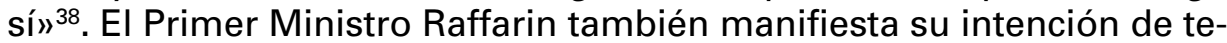
ner parte activa en la campaña ${ }^{39}$ si bien, tanto desde la izquierda favo-

33 Cfr. Le Monde, 11 de marzo de 2005, p. 1.

${ }^{34}$ Cfr. Le Monde, 4 de marzo de 2005, p. 1.

35 Cfr. Le Monde, 2 de marzo de 2005, p. 8.

36 Cfr. Le Monde, 3 de marzo de 2005, p. 6.

37 El anuncio del Elíseo "El Presidente ha decidido..." no deja lugar a dudas. Chirac fue más colegial con ocasión del referéndum sobre el Tratado de Maastricht, dejando que se anunciara la fecha a la salida de del Consejo de Ministros. Cfr. Le Monde, 6 y 7 de marzo de 2005 , p. 6.

38 Idem, id. ibid.

39 En una entrevista publicada por Le Monde, Raffarin señala cinco razones para votar si: La primera que el voto afirmativo es un voto de urgencia, pues se multiplican los desequilibrios económicos y políticos y Europa puede suponer un punto de encuentro entre el choque de civilizaciones, tanto en el seno de la ONU, para que haya mayores derechos, como de la OMC, para que haya más justicia; también se contribuye a mejorar el medio ambiente. La segunda es de tipo político: la Constitución Europea permitirá reafirmar la democracia desde el punto de vista políticoadministrativo. La tercera es de tipo social: se promoverá el empleo y el progreso social, se irá más lejos en la igualdad entre hombre y mujer y en la lucha contra la 
rable al Tratado como desde la derecha gobernante, se le anima a no implicarse demasiado para no fomentar el voto negativo como sanción al Gobierno ${ }^{40}$.

François Bayrou, presidente de la UDF (centro derecha) y socio político de $\mathrm{Chirac}^{41}$ parece querer dejar a los líderes de la UMP el mayor protagonismo, pues no realiza su primera reunión pública por el "sí» hasta primeros de abril.

Los parlamentarios del Partido Socialista, que han apoyado mayoritariamente la reforma, se muestran oficialmente favorables al Tratado y cierran filas en torno a su líder François Hollande. Este anuncia formalmente una actuación conjunta del Partido Socialista en favor del sí y lanza un eslogan que ensalza el aspecto social del Tratado: "La Europa social pasa por el sí» ${ }^{42}$.

Sin embargo ya en los primeros días siguientes a la aprobación parlamentaria tiene lugar una división en el seno del PS. Una parte de los socialistas, liderados por Laurent Fabius, antiguo primer ministro con Mitterrand y actual número dos del PS, se muestra contrario al Tratado y critica a Hollande por hacerle el juego a Chirac ${ }^{43}$. Esta campaña separada liderada por Fabius aún no se encuentra claramente definida. El primer argumento que el ex líder socialista utiliza para justificar su escisión de la línea marcada por Hollande es que "confunde sus papeles con los de Chirac»" ${ }^{44}$. Se suma a esta campaña separada Henri Em-

exclusión. La cuarta es de tipo económico: la agricultura y pesca europeas necesitan las ayudas europeas. Finalmente, en la quinta razón Raffarin sostiene que la nueva Europa regida por la Constitución reforzará la dimensión cultural europea (cfr. Le Monde, 4 de marzo de 2005, p. 1 y 15).

40 Cfr. Le Monde, 6, 7 de marzo de 2005, p. 6.

41 Recordamos que Bayrou sustituyó a Raymond Barre en la presidencia de la UDF. Vio frustrada su ambición de ser el tercer hombre en las presidenciales de 2002 y de prepararse así para la cita de 2007. Tras las legislativas, su partido se vio absorbido por la UMP (obtuvo 29 escaños de 577, frente a los 67 de que disponía en la anterior Asamblea).

42 Cfr. Le Monde, 13 de abril de 2005, p. 6.

43 El apoyo de Hollande a Chirac es castigado durante una manifestación el 5 de marzo, en la que el líder socialista es abucheado; Fabius comenta "se veía venir". (cfr, Le Monde, 8 de marzo de 2005, p. 8). A partir de este momento se irá acentuando la confusión de los votantes del partido socialista sobre cuál es realmente la posición socialista en este referéndum. Como reacción a estas actitudes disidentes el socialismo oficial recuerda que los defensores del "sí» dentro de su partido son el $60 \%$, según el referéndum interno celebrado el 1 de diciembre de 2004 (cfr. Le Monde, 13 y 14 de marzo de 2005).

${ }^{44}$ Cfr. Idem, id., ibid. 
manuelli, ex secretario del PS, pese a ser un federalista convencido y a haber votado junto con Laurent Fabius por Maastricht en $1992^{45}$.

En el seno de Los Verdes, el tercer grupo que apoya la Constitución Europea, la aprobación del Tratado tuvo lugar por una escasa mayoría en el referéndum interno organizado a comienzos de febrero. En el Consejo Nacional del 12 y 13 de marzo se lanza una campaña para defender el voto afirmativo. Para asegurarla, la dirección del partido, a cargo de Dominique Voynet, sostiene que hay que evitar "estigmatizar" a los partidarios del no e indica que hay que captarlos hacia el "sí". Como consigna en la campaña se prohíbe a los partidarios del "no» expresarse públicamente y a los del "sí» realizar actos comunes con el PS o la UDF ${ }^{46}$.

Jean-Pierre Chevenement, presidente de honor del MRC, también inicia una campaña por el "no" el 9 de marzo, campaña que tiene, sin embargo, un trasfondo principalmente nacionalista republicano.

También tiene un sentido nacionalista, pero de extrema derecha, la campaña llevada a cabo por el líder del FN, Jean-Marie Le Pen. Es un antieuropeísta convencido que ya votó en contra del Tratado de Roma. Su argumento principal es que "si Francia vota sí, desaparecerá» ${ }^{47}$. La táctica del partido en esta primera fase es no dejarse ver mucho al principio para no "diabolizar el no", lo que en realidad pone de manifiesto la falta de organización interna del partido ${ }^{48}$.

Completan el campo del "no», en la derecha, el MPF (Movimiento por Francia) liderado por Philippe de Villiers (derecha soberanista) ${ }^{49}$, que ya en enero de 2005 había iniciado su campaña en contra del Tratado y, en la izquierda, sumándose a las minorías socialistas, los trost-

${ }^{45}$ Cfr. Le Monde, 13 y 14 de marzo de 2005. En un comentario muy poco afortunado y criticado tanto por los socialistas de las dos campañas asemeja el "sí» socialista con los votos socialistas otorgados en 1940 al Mariscal Pétain. Tras las críticas surgidas de este comentario ha intentado justificarse sin éxito (cfr. Le Monde, 15 de marzo de 2005, p. 8).

${ }^{46}$ Cfr. Le Monde, 13 y 14 de marzo de 2005, p. 2.

47 Cfr. Le Monde, 19 de abril de 2005, p. 6.

48 Los seguidores de Le Pen se quejarán más delante de su falta de presencia en la campaña y critican la "deficiente preparación" que denota en los debates televisivos, sobre todo en cuestiones técnicas (cfr. Le Monde, 2 de mayo de 2005, p. 7).

49 Recordamos que este grupo concurrió por separado en las elecciones legislativas de 2002, tras las que pasó a figurar en el grupo de los no inscritos al rechazar formar parte de la asociación UMP (véase mi artículo "Las elecciones presidenciales y legislativas de 2002 en Francia», en Revista de Derecho Político, n. ${ }^{\text {os }}$ 55-56, UNED, Madrid, 2002, pp. 537 y ss.). 
kistas de la LCR (Olivier Besancenot), la ex Confédération paysane, de José Bové y el PCF (Marie-George Buffet), así como una minoría de Los Verdes (bajo el liderazgo de Francine Bavay) y otros movimientos asociativos, como el de CPNT (Caza, Pesca, Naturaleza y Tradición), de Jean Saint-Josse.

También están en contra de la ratificación los sindicatos franceses de los trabajadores, que se separan de los sindicados europeos ( la mayor parte de las confederaciones europeas sostienen el Tratado). En el referéndum interno celebrado en el seno de la central sindical GGT se apuesta por el "no" y se desautoriza a su secretario, Bernard Thibault.

A partir de 5 de marzo la prensa se hace eco de la división socialista y del malestar social reinante en el país y el miedo a que el resultado del referéndum sea negativo no abandona los titulares.

\subsection{Desarrollo de la campaña}

En plena campaña francesa, el 6 de abril, el Tratado sobre la Constitución Europea es ratificado en Italia por la vía parlamentaria ${ }^{50}$. El 1 de junio está prevista la ratificación en Holanda. En Europa se teme que el resultado de esta consulta se vea afectado por un "no" en Francia (la abstención se cifra en un $60 \%$ ).

La campaña, que se inicia con perspectivas favorables la ratificación del Tratado, bascula hacia el "no" ya en la primera quincena de marzo. Este giro viene propiciado por la división dentro del PS y, posteriormente, por la de los Verdes, dado que tanto el electorado de extrema derecha como el de extrema izquierda es un electorado convencido. A partir de aquí la UMP y la línea oficial del PS Ilevarán a cabo una campaña principalmente defensiva, desmintiendo los argumentos de los detractores del Tratado, lo que denota la carencia de preparación sólida y de estrategia conjunta del campo del "sí». El tema preferido por los partidarios del "no", el de la potencial fuga de empresas, que tiene su origen en la ampliación de la Unión hacia países del Este con mano de obra barata, viene refrendado por elevado desempleo y el bajo crecimiento económico nacional. Se convierte en el eje de la campaña, a semejanza de lo que ocurrió en los comicios de 2002 con el de la seguridad.

50 Confirmado por la cámara baja, en la cámara alta se cierra el procedimiento de aprobación por 217 votos contra 16 (cfr. Le Monde, 7 de abril de 2005.

(C) UNED. Revista de Derecho Político 


\subsubsection{Sondeos}

Tras un crecimiento progresivo desde el comienzo de la campaña, el "no" se instala por primera vez como ganador en los sondeos el 17 de marzo, debido principalmente al cambio en la intención de voto dentro de los simpatizantes socialistas ${ }^{51}$. A partir de aquí seguirá vencedor en las encuestas ${ }^{52}$ hasta primeros de mayo. Por estas fechas el sondeo realizado estima entre los votantes socialistas una proporción de "no" - "sí" del $51 \%$ - 49\% y para la totalidad de los encuestados, de $48 \%$ $52 \%{ }^{53}$. Este ascenso del "sí» coincide, paradójicamente, con la fiesta del trabajo. Sin embargo el "no" se instala definitivamente en los sondeos desde comienzos de la segunda mitad de mayo. El "sí» baja principalmente, como hemos dicho, entre los votantes del PS (por el efecto combinado de la actuación de Laurent Fabius y los comentarios de Jacques Delors sobre la eventualidad de que exista un "plan B») y sólo sigue siendo mayoritario en la derecha parlamentaria, pero tras bajar seis puntos. Un cuarto de los franceses manifiestan estar aún inde$\operatorname{cisos}^{54}$. A cuatro días del referéndum el «no» domina absolutamente los sondeos ${ }^{55}$. El último sitúa la intención de voto en contra del Tratado en un $54 \%$ (un $52 \%$ de los encuestados piensa que el rechazo a la Constitución permitirá a Francia negociar) ${ }^{56}$. A partir este momento nadie, en especial políticos franceses y europeos, duda de un rechazo al Tratado el 29 de mayo.

\subsubsection{La actuación de los medios audiovisuales}

La campaña oficial en televisión y radio se inicia el 16 de mayo a las $0,00 \mathrm{~h}$. Durará hasta el 28 de mayo a medianoche. Se rige por unas complejas reglas de equidad, en vigor desde el 4 de abril hasta la fecha

51 Sondeo efectuado por el Instituto CSA para Le Parisien.

52 Éste llega a alcanzar un $53 \%$ en la primera quincena de abril (sondeo TNS-Sofres y Unilog para Le Monde y RTL), e incluso un $56 \%$ de las intenciones de voto tras la aparición pública de Chirac en la Sorbonne el 14 de abril (Sondeo CSA e IFOP publicado el 16 de mayo).

53 Sondeo TNS-Sofres y Unilog para Le Monde, CTL y LCl. Cfr. Le Monde, 2 de mayo de 2005, p. 6

54 Sondeo TNS-Sofres y Unilog, publicado el 17 de mayo por Le Monde, RTL y LCE (cfr. Le Monde, 18 de mayo de 2005, p. 1).

55 Cfr. Le Monde, 26 de mayo de 2005, p. 1.

56 Sondeo TNS-Sofres y Unlig para Le Monde, RTL y LCl (cfr. Le Monde, 27 de mayo de 2005). 
del referéndum. Para respetarlas, la mayoría de medios oficiales descarta invitar a personales políticos a sus programas de variedades, fuera de lo que corresponde estrictamente a la campaña ${ }^{57}$.

En los medios participan ocho partidos políticos: La UMP, la UDF, el PS, el PCF, Los Verdes, el MPF, la RPF y el FN. Se establece, para los partidarios del "sí», un tiempo de antena de noventa minutos en cada medio y, para los del "no", de cincuenta ${ }^{58}$.

El 3 de mayo de 2005 el CSA (Consejo Superior de Medios Audiovisuales) solicita a numerosas cadenas que reequilibren su tiempo en antena (entre el 4 y el 29 de abril habían consagrado el $63 \%$ de su tiempo a los defensores del Tratado, contra sólo un $37 \%$ dedicado a sus detractores). Esta advertencia del CSA será utilizada por éstos para denunciar la arrogancia de los defensores del «sí»"

\subsubsection{Campaña a favor del Tratado sobre la Constitución Europea}

El campo del "sí» aúna posiciones distintas desde el punto de vista político. En efecto sería impensable ver juntos a la UMP con el PS y los Verdes en una campaña por unos comicios nacionales ${ }^{60}$. Estos partidos no utilizan los mismos argumentos - sólo tienen en común el ser europeistas-.

Durante la primera parte de la campaña, el creciente calado de los argumentos a favor del "no" entre el electorado obligará a realizar una campaña fundamentalmente defensiva, contradiciendo los ataques de aquellos. En la segunda parte de la campaña la estrategia de la mayoría gobernante y de la línea oficial del PS será la de potenciar la idea inicial de informar, ensalzando los valores europeos ${ }^{61}$, e intentar captar así al elevado número de indecisos, de los que depende la suerte de la campaña.

57 Cfr. Le Monde, 4 de abril de 2005, p. 8.

58 Cfr. Le Monde, 5 de abril de 2005, pp. 1 y 17 de mayo de 2005, p. 6.

59 Cfr. Le Monde, 19 de mayo de 2005, y 29-30 de mayo de 2005, p. 5.

60 Debe hacerse mención aparte de la segunda vuelta de las presidenciales de 2002, donde se dieron las circunstancias extremas conocidas, ya mencionadas supra (p. 18 )

61 Cfr. Le Monde, 17-18 de abril de 2005, p. 8. 


\subsubsection{El segmento de derechas favorable al Tratado}

\section{Está compuesto por la UMP y la UDF (centro-derecha) de Fraçois Bayrou.}

Durante toda la campaña la mayoría gobernante muestra una actitud negativa hacia el resultado del referéndum y dramatizará los efectos de un rechazo de Francia al Tratado. Estas actitudes crearán un efecto contrario al deseado pues alimentará el rechazo de parte del electorado ${ }^{62}$.

En el terreno de la política interna, Raffarin, cuando los sondeos aún le son favorables, toma medidas de urgencia para asegurar la ratificación del Tratado. Para ello adopta una actitud dialogante con los sindicados y manifiesta estar atento a las recientes reivindicaciones sociales ${ }^{63}$. A finales de primera mitad de marzo anuncia una revalorización de los salarios, lo que inquieta al sector privado y a la mayoría parlamentaria.

Tras la victoria del "no" en los sondeos de la segunda mitad de marzo, Raffarín reúne a sus ministros el 28 de marzo para que, en lo sucesivo, se ponga acento en las ventajas del Tratado. Ya desde estas fechas, en el seno de la UMP se teme que haya un voto de sanción contra el Gobierno ${ }^{64}$. Cuando los sondeos empiezan a ser contrarios a la ratificación el primer ministro Raffarin intenta importancia a las encuestas y señala que un mes antes del referéndum sobre Maastricht la intención de voto negativo se situaba entre un $53 \%$ y un $54 \%{ }^{65}$.

François Bayrou, el líder de la UDF, durante un mitin en Lión hace un Ilamamiento a la unidad del "sí» y propone «dejar a un lado las diferencias políticas habituales»"6.

Partidarios del "sí» dentro de la mayoría, entre ellos Bayrou, hacen un Ilamamiento a Chirac para que se implique más en la campaña. La primera aparición pública del Jefe de Estado a favor del Tratado tiene lugar el 15 de abril ante un grupo de jóvenes durante dos horas ${ }^{67}$. El resultado de esta en-

\footnotetext{
62 En efecto, se suceden comentarios del tipo «hay que evitar expresiones que creen miedo", como el anteriormente citado de Raffarin, o "no tengáis miedo» (Chirac a los jóvenes de la Sorbonne).

63 Cfr. Le Monde, 15 y 16 de marzo de 2005.

${ }^{64}$ En efecto, este ascenso alarmante del «no» supone un fuerte golpe para el PS y la derecha parlamentaria, pese a la incertidumbre que representa el elevado número de indecisos (cfr. Le Monde, 23 de marzo de 2005, p. 8).

65 Cfr. Le Monde, 16 de abril de 2005, p.15.

66 Cfr. Idem, id. ibid.

67 Esta forma de intervención es inédita en el Jefe del Estado, que siempre ha preferido las alocuciones televisadas.
} 
trevista recibe una valoración sumamente negativa de los medios y de los políticos en general (incluso entre algunos representantes de la UMP). Tras la misma, la intención de voto negativo a la Constitución sube a un $56 \%$ según los sondeos ${ }^{68}$. En efecto, durante esta entrevista Chirac utiliza expresiones como la ya citada de "no hay razones para sentir miedo" o "no comprendo el pesimismo de los jóvenes, eso me da pena» ${ }^{69}$ y fustiga una vez más la corriente "ultraliberal" y "anglosajona-atlantista ${ }^{70}$, pero no consigue escapar a las críticas a la política social del Gobierno ${ }^{71}$.

En adelante el Presidente permanecerá entre bastidores, sin duda aconsejado por miembros de su partido ${ }^{72}$. Se constata, por lo tanto, su pérdida de liderazgo en la campaña, lo que le impedirá convertirse, como era su intención al convocar la consulta, en el maestro de ceremonias de la ratificación ${ }^{73}$. Preguntado sobre su responsabilidad y la del Gobierno en el auge del "no" admite que, en efecto, esa responsabilidad existe, pero, en lo tocante a la política gubernamental, insiste en que no debe mezclarse ésta, que tiene sus propias exigencias, con una decisión fundamental como la de la Constitución Europea ${ }^{74}$.

La segunda aparición de Chirac no tendrá lugar hasta el 3 de mayo, en TF1. En esta ocasión, aunque intenta informar de las ventajas del "sí»" 75 , consigue evitar expresar argumentos atemorizadores sobre las consecuencias de un rechazo al Tratado. Lo más destacable de esta aparición de Chirac es, sin embargo, su cambio de actitud sobre su responsabilidad en el resultado del referéndum, pues sostiene: "el «no" no sería mi fracaso, sino el fracaso de Francia» ${ }^{76}$.

68 Sondeo CSA e IFOP, publicado el 16 de abril (cfr. Le Monde, 17-18 de abril de 2005, p. 1).

69 Cfr. Le Monde, 16 de abril de 2005, p. 9.

70 En lo que respecta a la Constitución sostiene que la lógica de ésta no es liberal, no responde a la economía de mercado.

71 Idem, id., ibid.

72 Según señala el diario Le Monde (20 de mayo de 2005), Nicolas Sarkozy, presidente de la UMP, está convencido de que las intervenciones del Presidente movilizan el «no».

73 La pérdida patente de liderazgo de Chirac será aprovechada por Nicolas Sarkozy, en la actualidad presidente de la UMP que, ya en unas declaraciones publicadas a principios de abril declara no descartar la posibilidad de enfrentarse a Chirac en 2007 (cfr Le Monde, 2 de abril, p. 9).

${ }^{74}$ Cfr. Idem, id., ibid. Le Monde, 16 de abril de 2005, p. 9.

75 Señala, como ventajas de la aprobación del Tratado, el refuerzo del peso específico de Francia, la mejor organización social y progreso social, salvaguardando los servicios públicos.

${ }^{76}$ Cfr. Le Monde, 5 de mayo de 2005, pp. 1, 7 y 8. 
En la segunda mitad de abril Dominique de Villepin confirma implícitamente su candidatura al Elíseo, lo que es desmentido por el primer ministro Raffarin, que, tras una entrevista con el Jefe del Estado, asegura que aún cuenta con la confianza del Jefe del Estado ${ }^{77}$. En realidad detrás de esta posible nominación subyace el temor a nombrar a Sarkozy, ex ministro de interior y de economía, que es el favorito a Presidente en todas las encuestas. Ante estos rumores sobre la posible nominación de Villepin a Matignon estalla la unidad del Gobierno ${ }^{78}$, si bien Sarkozy seguirá apoyando a Chirac en la campaña, pero con menos presencia ${ }^{79}$. Posteriormente se estimará que los argumentos de éste último, excesivamente liberales ${ }^{80}$, han contribuido a la fuga de votantes socialistas al campo del "no»" ${ }^{81}$. Para unos ésta es la razón de la relativa desaparición de Sarkozy en la campaña, mientras que otros consideran que es él mismo el que se ha retirado, para no figurar demasiado en el "bando de los perdedores" ${ }^{82}$.

En la segunda mitad de mayo todo hace prever que el Tratado será rechazado en referéndum. Raffarin evoca el riesgo de una crisis económica si gana el "no" ${ }^{83}$. Recalca que Francia se pronunciará una vez y que no habrá una segunda opción y, al igual que hiciera Chirac, a sólo cuatro días de la consulta, se niega a vincular su suerte al resultado de ésta ${ }^{84}$.

El 26 de mayo, cuando ya no hay duda de la victoria del «no» tras el último sondeo realizado, Chirac lanza el último llamamiento en televisión a la aprobación del Tratado. En esta alocución resulta mucho más convincente que en las anteriores intervenciones. Recuerda la dimensión histórica del escrutinio y sitúa a los electores ante su responsabilidad, a la vez que se compromete a dar una nueva impulsión a la ac-

77 Cfr. Le Monde, 19 de abril de 2005, pp. 1 y 6.

78 Sarkozy, enemigo de Villepin (ambos se consideran los herederos de Chirac) sostiene que de producirse la misma la lucha entre ambos será feroz en dos años (cfr. Le Monde, 24-25 de abril de 2005, p. 1).

79 Cfr. Le Monde, 17 de mayo de 2005.

80 Defiende, por ejemplo, la facilidad en los despidos y la supresión del beneficio de la seguridad social para las clases mejor situadas.

81 Para Bayrou, la tesis liberales de Sarkozy han sido responsables de la fuga de un $12 \%$ de los electores que inicialmente se decantaban por el "sí» (cfr. Le Monde, 21 de mayo de 2005, p. 5)

82 Cfr. Idem, id, ibid.

$83 \mathrm{Cfr}$, Le Monde, 19 de mayo de 2005, p. 7.

84 Recuerda que «la acción del Gobierno está permanentemente impulsada por el Jefe de Estado", para evitar convertirse en "chivo expiatorio" (cfr. Le Monde 26 de mayo de 2005, p. 7). 
ción del Gobierno, hacia una mayor solidaridad y dinamismo "para vivir mejor el pacto republicano". Implícitamente, reconoce que existen motivos para sancionar al Gobierno, pues alega que no se trata de decir "sí" al Gobierno, sino a Europa, y sigue evocando el miedo al aislamiento y pérdida de protagonismo de Francia en Europa ${ }^{85}$. Los defensores del Tratado alaban, en general, esta alocución de Chirac, si bien lamentan que el Jefe del Estado no haya conseguido mostrarse convincente sino cuando ya es demasiado tarde. En el partido socialista se ve de buen grado el reconocimiento de Chirac de la existencia de motivos para sancionar al Gobierno ${ }^{86}$.

\subsubsection{El segmento de izquierdas favorable al Tratado}

Esta formado por las líneas oficiales del PS y de Los Verdes. La izquierda liberal aparece más dividida que la derecha parlamentaria, desde la escisión de la línea socialista seguidora de Laurent Fabius, a la que pronto se suma otra línea separada de la oficial de Los Verdes. La división existe, por consiguiente, tanto dentro de estos partidos, como entre estos y el PCF.

La situación del PS es, por lo tanto, radicalmente opuesta a la de la campaña por el Tratado de Maastricht ${ }^{87}$. El eslogan oficial de que la Europa social pasa por el sí no logra convencer, porque gran parte del electorado francés piensa que Europa pone en peligro su modelo social y que será difícil mantener los servicios públicos. Paradójicamente, la campaña de Mitterrand en 1992 por el Tratado de Maastricht presentaba a Europa como una solución a los problemas sociales del país. Ahora, en cambio, Europa se ve como un factor acelerador de esos mismos problemas $^{88}$.

Pese a la división interna sobre la ratificación, el PS anunciará a mediados de marzo un nuevo proyecto para 2007 con ideas "auténticamente reformistas". Se insiste en la idea de Martine Aubry sobre las

85 Cfr. Le Monde, 28 de mayo de 2005, p. 2.

${ }^{86}$ Cfr. idem, id., ibid.

87 Michel Noblecout recuerda que entonces Jean-Pierre Chevènement transformó su corriente "Socialismo y República» en el "Movimiento por los Ciudadanos" para encauzar el "no" de los socialistas. Sin embargo - prosigue - ahora se asiste a una escisión y la línea no oficial marcada por Fabius se refugia en el paraguas político y social del PS, para decir lo contrario que sus militantes (cfr. "Analyse" en Le Monde, 21 de marzo de 2005, p. 1).

${ }^{88}$ Cfr. JAfrRÉ, Jèrome, "Analyse", en Le Monde, 13 de abril de 2005, p.p 1 y 6. 
nuevas desigualdades y en la de Jack Lang sobre la necesidad de una renovación en la democracia ${ }^{89}$.

François Hollande, dirigente del PS, a semejanza de Chirac pierde, también desde el principio, las riendas de la campaña. En realidad, su autoridad no ha dejado de ser puesta en tela de juicio desde el congreso de Dijon de 2003, en el que resultó elegido. Durante su primera reunión pública a finales de marzo en Marsella hace un Ilamamiento «a todos los que sufren la política de la derecha para que no tomen a Europa como chivo expiatorio" y reserven su justificada sanción para los comicios de $2007^{90}$. Más adelante cometerá el error político de acusar a los defensores del "no" de "hacerle el juego a Le Pen", lo que le valdrá duras críticas dentro de su partido, tras lo que se verá obligado a rectificar ${ }^{91}$.

La situación dentro del PS hace prever que tras el referéndum habrá que celebrar un referéndum de clarificación, como piden Fabius y Emmanuelli, líderes de la línea escindida.

A lo largo de la campaña Holland irá limitando sus intervenciones para dar el relevo a Jospin, más considerado según la opinión pública. Este intervendrá en cuatro ocasiones durante la campaña. Su primera aparición desde su derrota del 21 de abril de 2002 tiene lugar en televisión el 28 de abril, para argumentar que votar contra el Tratado equivale a sancionar a Francia. Durante la misma señala que existe una compatibilidad de "síes", pero una incompatibilidad de "noes", e insiste en que los problemas internos no deben solucionarse tomando a Europa como rehén ${ }^{92}$. En los días previos al referéndum, Jospin se concentrará en denunciar esta contradicción de los socialistas detractores del Tratado, "que dicen ser responsables y sumarse a las preocupaciones europeas $y$, sin embargo, votan no" ${ }^{93}$. Al final de la campaña se muestra combativo pero más relajado y manifiesta sentirse satisfecho por haber conseguido presentar la Constitución Europea como un texto neutro, pero evoca el riesgo del aislamiento de Francia ${ }^{94}$.

89 Cfr. Le Monde, 16 de marzo de 2005, p. 8).

90 Le Monde, 2 de abril de 2005, pp. 1 y 7.

91 Cfr. Le Monde 12 de abril de 2005, p. 6.

92 En respuesta a estas declaraciones, el PCF ironiza sobre el hecho de que regrese justo ahora "a impartir a la izquierda una lección" (cfr. Le Monde, 29 de abril de 2005, p. 7).

93 Cfr. Le Monde, 21 de mayo de 2005, p. 7.

94 Entrevista realizada el 24 de mayo en TF1 (cfr. Le Monde, 26 de mayo de 2005, p. 1). 
A final de campaña François Hollande, se desmarca, al igual que Chirac y Raffarin, del resultado del referéndum, al afirmar que "el 29 de mayo no será el PS quien pierda, sino Europa», al tiempo que sostiene que hay que aglutinar a la izquierda ${ }^{95}$.

La línea oficial de Los Verdes favorable al Tratado defenderá durante la campaña el argumento de que la Constitución Europea es el primer paso político de Europa (Maastricht, si bien tenía un claro objetivo político, no ofrecía ninguna definición). Se reprocha a los detractores del Tratado «no entender que una Constitución es una relación de fuerzas jurídicas e implica un combate cotidiano para hacerla evolucionar» y se insiste en la necesidad de proponer un modelo social y en que la Constitución europea ofrece mecanismos para construir ese modelo ${ }^{96}$.

En la segunda mitad de abril, al igual que en el PS en marzo, estalla la división en el seno de los Verdes. Su Consejo decidirá el 26 de abril, contra el dictamen de su secretario general, Yann Wehrling, que todos los militantes podrán expresarse libremente ${ }^{97}$. Así, mientras el PS, impulsados por Jospin, intenta imponer su disciplina, Los Verdes se saltan las reglas pactadas para la campaña. La izquierda del "sí» no consigue dar una imagen de unión, lo que acentúa la confusión.

Ante la instalación del "no" en los sondeos, a sólo diez días del referéndum los grupos políticos europeos de izquierda favorables al "sí» contraatacan para defender el Tratado. El miércoles 18 de mayo representantes europeos socialistas, socialdemócratas y verdes participan en un mitin organizado por el PS francés en el Cirque d'Hiver ${ }^{98}$.

Entre las valoraciones manifestadas en estos días por líderes socialistas, destaca la de Dominique Strauss-Khan, que sostiene que para que el PS venza las presidenciales de 2007 debe ganar el «sí»"

\subsubsection{Campaña en contra del Tratado sobre la Constitución Europea}

El campo del «no» aúna, al igual que el campo del «sí», partidos de extrema derecha, izquierda y centro. Lo más paradójico es, sin embar-

95 Cfr. Le Monde, 27 de mayo de 2005, p. 8.

96 Estos, indica la línea oficial, sostienen que el modelo francés no tiene respuesta para las mundializaciones y no se equivocan ; de ahí la necesidad de proponer un modelo social. Cfr. Le Monde 17 de mayo de 2005, p. 6.

97 Cfr. Le Monde, 28 de abril de 2005, p.

98 Cfr. Le Monde, 20 de mayo de 2005, p. 7.

99 Debate televisado el 26 de mayo en France- 2. 
go, que esta asociación por el "no" implica que dentro de un mismo bando se hallen europeístas (por ejemplo, los socialistas Laurent Fabius o Henri Emmanuelli, que defendieron junto a Mitterrand el Tratado de Maastricht) con soberanistas (Le Pen o Villiers), si bien todos coinciden en el temor a las deslocalizaciones, un importante argumento en común teniendo en cuenta que es el tema principal de la campaña. Fuera de este punto de coincidencia, los primeros acusan a la Constitución de ser neoliberal, basándose en su Parte III. Curiosamente, esta parte está ya incluida en otros textos anteriores ya aprobados y no es susceptible de modificación por los Estados (se omite, sin embargo, esta circunstancia). Los segundos la acusan de que hará desaparecer Francia como nación. Este argumento tampoco está exento de demagogia pues al examinar el desarrollo de la campaña, sorprende que la parte donde se explica la repartición de competencias entre la Unión Europea y los países miembros, que debería de haber sido capital en el debate, apenas esté presente ${ }^{100}$.

4.2.4.1. El segmento de derechas contrario al Tratado se consolida considerablemente durante la campaña. Está compuesto por FN y Villiers. Si bien el FN, cuyos electores son votantes convencidos del "no", domina bastante poco la campaña (menos aún que la de Maastricht), el conjunto de la derecha contraria al Tratado consigue ir ampliando sus argumentos, que finalmente se concretan, según Phillipe de Villiers, secretario de MPF en la amenaza de la entrada de Turquía, en el modelo social y económico previsto en el Tratado y en los problemas inherentes a la soberanía y a la democracia ${ }^{101}$. Critican que la derecha gobernante, después de haber organizado un referéndum, les prohíba en la práctica votar "no". Los electores del Frente Nacional y los de grupos soberanistas representan el $50 \%$ de los opositores al Tratado. Al final de la campaña, de Villiers, tomando ventaja de la escasa presencia de Le Pen, se consolida como el representante en los medios de este segmento del electorado ${ }^{102}$.

En este grupo cabe pueden incluirse también asociaciones que defienden el "no", como la asociación "Debout la République» del diputado UMP Nicolas Dupont, que está presente en todos los departamentos, o la asociación "Cercle nation et République" presidida por el diputado de UMP por Yvelines, Jacques Myard ${ }^{103}$.

100 Véase la entrevista a Valèry Giscard d'Estaing (Le Monde, 15 de junio de 2005, p. 15).

101 Además, critica Philippe de Villiers que el referéndum sea un dictado, que no admita más que una respuesta (cfr. Le Monde, 8 de abril de 2005).

102 Cfr. Le Monde 26 de mayo de 2005, p. 1

103 Cfr. Le Monde, 18 de mayo de 2005, p. 6. 
4.2.4.2. El segmento de izquierdas contrario al Tratado está liderado, como se ha dicho, por Laurent Fabius (por ser el político más antiguo y de más grado). El mismo día de la aparición de Jospin en France2, el 28 de abril, Fabius explicará las razones de su rechazo al Tratado en la Universidad de Columbia. En su campaña declara perseguir un doble objetivo, "unir a los socialistas y al conjunto de las fuerzas de izquierda ${ }^{104}$. Con este propósito se acerca inusitadamente a la izquierda antiliberal, desde José Bové, portavoz de la LRC, a la organización altermundialista Attac ${ }^{105}$, olvidando las críticas que le extrema izquierda le dirigió en 2002. El único límite que el ex dirigente socialista se impone en esta unión con la extrema izquierda es el de no realizar mítines conjuntos. Poco a poco va definiendo su campaña, que centra en el efecto de la fuga de empresas sobre el empleo.

Los Verdes separados de la línea oficial han decidido aproximarse al PCF y a la LCR (línea oficial que ha preferido unirse en la campaña al PS oficial). De la Constitución Europea denuncian que legitima "liberalismo" en lugar de "productivismo". Realizan un mitin conjunto por la unidad de la izquierda favorable al "no", en compañía de los grupos de extrema izquierda. Para este mitin se prohíben las alusiones al PS. EI Partido Comunista se felicita por la profundización en el compromiso mostrada por los grupos participantes, si bien la dirección de estos Verdes escindidos recuerda que la campaña es "una red de movilización, no de un partido ni de una candidatura para 2007"106.

En la recta final de la campaña el conjunto de la izquierda del «no», sirviéndose del eslogan "todos juntos", utilizado en las huelgas, proclama la necesidad de que la unión del "no" de izquierdas perdure. Los sindicatos de los trabajadores sostienen que, sea cual sea el resultado del referéndum, la cúpula gobernante «no podrá eludir una cita con ellos después del 29 de mayo" ${ }^{107}$.

104 Estas declaraciones las hace al diario de extrema izquierda "Humanité», que por primera vez publica una entrevista hecha a un socialista Utiliza la táctica del miedo vaticinando una serie de males sociales si gana el sí (reducción funcionarial, negociación con los sindicatos a favor de los empresarios, intervención europea en la seguridad social o aumento de las tarifas GDF) (cfr Le Monde, 18 de mayo de 2005, p. 6). Jospin respnde a estas declaraciones argumentando que «para unir a la izquierda, más le habría valido respetar su voto" (cfr. Le Monde, 21 de mayo de 2005, p. 7).

105 Esta organización, que ahora aboga por el "no», consuma así su separación del PS, partido con el que trabajó durante la época del encuentro altermundialista de Porto Alegre, en Brasil, antes de los comicios de 2002 y del que recibió subvenciones.

106 Cfr. Le Monde, 18 de mayo de 2005, p. 6.

107 Cfr. Le Monde, 28 de mayo de 2005, p. 3. 


\section{RESULTADOS DEL REFERÉNDUM}

Los resultados de la consulta son los siguientes:

\subsection{Exposición de los resultados ${ }^{108}$}

$\begin{array}{ll}\text { Votantes: } & 69,74 \% . \\ \text { Abstención: } & 30,26 \% \\ \text { Blancos o nulos: } & 1,76 \% \\ \text { Votos expresados: } & 67,98 \% \\ \text { Votos en contra del Tratado: } & 54,87 \% \\ \text { Votos a favor del Tratado: } & 45,13 \%\end{array}$

\subsection{Valoración}

4.2.1. Destaca el considerable índice de participación, lo que constituye un indicio de que la cuestión Europea ha desatado las pasiones francesas. Con casi un $70 \%$, se ha situado a un nivel parecido al de Maastricht y contrasta con el bajo índice participativo que la misma consulta tuvo en España.

4.2.2. El «no», por lo que tiene de protesta a las tesis oficiales, parece haber movilizado mucho más al electorado que el "sí». Esto es un indicador de que el "no" ha sido tanto un rechazo de la política de Chirac como de Europa. No puede decirse que este "no", franco y masivo, sea fruto de la desinformación, pues un elevado porcentaje declara haber leído el texto, que se ha distribuido gratuitamente. Cosa distinta es que se haya comprendido adecuadamente.

4.2.3. Los sondeos indican que en el transcurso de la campaña se ha producido un viraje importante hacia el "no». Este cambio en la intención de voto parece haber afectado, principalmente, a las clases medias y a los jóvenes. Estos han mostrado que constituyen un nuevo desafío (citamos, por poner un ejemplo, las manifestaciones de los estudiantes previas a la campaña, en contra de la ley Fillon). Chirac no eligió por puro azar que su primera intervención pública tuviera lugar ante un grupo de jóvenes, al contrario, ésta fue deliberada, aunque erróneamente calculada ${ }^{109}$.

108 Fuente Le Monde, 31 de mayo de 2005.

109 Cfr. Le Monde, 10-11 de abril de 2005. 
4.2.4. Finalmente, en cuanto a la repartición geográfica del escrutinio, el "no" ha resultado mayoritario en las ciudades pequeñas y en el medio rural, mientras que el "sí» ha ganado con amplia mayoría en la mayor parte de las grandes ciudades (París, Lyon, Burdeos, Nantes, Estrasburgo y Toulouse), con excepción de Marsella, lo que parece coherente con el principal temor que ha azotado la campaña, el desempleo, pues las zonas rurales y las pequeñas ciudades suelen ser las que más acusan este mal social. Asimismo todos los estudios muestran que el "no" ha ganado con amplia mayoría en las zonas con mayor índice de desempleo y donde está teniendo lugar la deslocalización de empresas $^{110}$. Según los sondeos, un $79 \%$ de los obreros franceses han votado "no" el 29 de mayo, mientras que en los cuadros superiores en las profesiones liberales el rechazo a la Constitución ha sido de un $35 \%^{111}$.

\section{CONCLUSIONES}

6.1. Hay que destacar, en primer lugar, que la campaña del referéndum ha aunado en bandos opuestos a fuerzas políticas que sería imposible imaginar juntas en unos comicios nacionales. El tema de la consulta lo ha permitido. Lo paradójico, sin embargo, es que lo que empezó siendo un debate sobre Europa ha terminado asemejándose a unos verdaderos comicios nacionales.

6.2. Desde prácticamente el inicio de la campaña se ha asistido a una dramatización de la situación por parte de los medios informativos. Esta dramatización no ha dejado de estar presente en las publicaciones sobre la evolución en la intención de voto, lo que puede también puede haber condicionado el resultado ${ }^{112}$.

6.3. Avala la idea del punto I la comparación de este escrutinio con el de Maastricht. Según apunta Daniel Cohen, se suele olvidar que el Tratado de Maastricht fue aprobado por justa mayoría. El cómputo y

110 Cfr. El País, 1 de junio de 2005, p. 2.

111 Asimismo entre los trabajadores de carácter temporal, un $71 \%$ ha votado no a Europa, Cfr. Le Figaro, 2 de junio de 2005.

112 Como ejemplo de esta dramatización cfr. Le Parisien, 18 de marzo de 2005, en la página 1 aparece «¿NO? en letras rojas. En las páginas interiores figuran los resultados del primer sondeo realizado por el CSA, que sitúa el "no" en un 51\%. Ilustra la creencia de que los sondeos condicionan la opinión pública el hecho de que para el referendum sobre el mismo tema organizado para el 10 de julio en Luxemburgo se haya prohibido la publicación de sondeos desde un mes antes de la consulta (cfr. Le Figaro, 9 de julio de 2005). 
comparación de los grupos que entonces estuvieron y que ahora están a favor y en contra de cada Tratado confirma que ambas consultas han sido más una cuestión de política interna que un debate sobre Europa. En efecto, en 1992 la derecha votó mayoritariamente contra Maastricht, cuando tendría que haber apoyado el Tratado, pues éste dictaba una ortodoxa monetaria y presupuestaria a los países miembros, factor que suele servir más a los intereses de la derecha que a los de la izquierda. A la inversa, el Tratado sobre la Constitución Europea que ahora se ha sometido a ratificación ofrece el primer esbozo de democracia parlamentaria para la Unión Europea, lo que debería haber obtenido el apoyo de los grupos democráticos de izquierda. En resumen, cuando la izquierda estaba en el poder, la derecha votó en contra $y$, viceversa, ahora que la derecha gobierna, la izquierda se opone, aduciendo que la Constitución es demasiado liberal, cuando lo cierto es que también contiene otros aspectos sociales que ni siquiera se han debatido en la campaña. Simplificando, el autor concluye que, en 1992, la izquierda más el centro-derecha sumó la mayoría justa para aprobar el euro. Ahora, en 2005, el Tratado sobre la Constitución Europea ha sido rechazado por la suma de la izquierda y la extrema derecha, lo que nos sitúa de nuevo en el escenario de las presidenciales y legislativas de $2002^{113}$. Habrá que esperar a 2007 para ver si el desencanto de los franceses, expresado de nuevo en este escrutinio, encuentra remedio en las presidenciales, o si, por el contrario, vuelve a producirse una situación parecida a la de los pasados comicios generales.

6.4. El resultado de la consulta que ahora nos ocupa muestra que la cólera contenida de los franceses se ha vuelto, una vez más, contra sus gobernantes. También ahora ha declarado Chirac haber entendido el mensaje de la población. Además ha reconocido que el rechazo al Tratado no significa una negativa a Europa, sino "una demanda de acción» y de "resultados" a los poderes públicos, tras lo que añade que el empleo será la "prioridad" y exigirá una "movilización nacional». Defiende la "eficacia" como único remedio para combatir el paro o la precariedad laboral ${ }^{114}$. Esto le dejaría vía libre para desplegar políticas muy dispares ${ }^{115}$, si no fuera porque también a prometido "hacer vivir y pro-

113 Cfr. "Analyse» en Le Monde, 17 de junio de 2005, pp. 16 y 17.

114 Cfr. El País, 1 de junio de 20005, p. 2.

115 En efecto, en lo sucesivo Chirac podrá optar por una política de preocupaciones sociales, por ejemplo, retardando la liberalización de los servicios públicos, o, al contrario, podrá decidirse por un una modernización acelerada, de forma que se pueda fortalecer la economía para conseguir un más fuerte crecimiento de la creación de empleo. Esta opción implica una política de claro corte neoliberalista y contra- 
gresar el modelo francés... en un ambiente de unión ${ }^{116}$, basado en un modelo social, distinto del anglosajón y que «no es sinónimo de inmovilismo" ${ }^{117}$. Esto excluye la opción de una política puramente liberal $^{118}$. La incompatibilidad entre lo declarado y lo que lo que expertos en economía consideran ser necesario para solucionar los dos grandes problemas económico-sociales del país ${ }^{119}$, así como la premura del calendario (quedan menos de dos años para los próximos comicios nacionales), hacen prever que Chirac no logrará convencer al electorado e invertir así la vertiginosa caída hacia su no-reelección que ha iniciado tras fracasar en esta consulta.

6.5. Como primera muestra de "haber entendido el mensaje» de la población, el Presidente ha aceptado la dimisión de su Primer Ministro y a continuación a nombrado a Dominique Villepin al frente del Gobierno, al tiempo que ha cambiado parte de la composición ministerial de éste. A Sarkozy le ha asignado la cartera de Ministro de Estado, con lo que se convierte en el número dos del Gobierno, y la de interior $^{120}$, que ya detentó. Esta débil maniobra institucional ha sido considerada por la opinión pública como frívola, comparada con la gravedad del mensaje que el pueblo francés ha querido hacer llegar al Jefe del Estado mediante su negativa a la Constitución Europea.

decir la argumentación seguida en la campaña, en la que constantemente ha atacado el liberalismo de corte anglosajón. De hecho, el rechazo de este modelo, que los detractores de la Constitución ven presente en ella, y que los asalariados interpretan como el universo de la competencia donde se pagan salarios muy bajos, ha sido una de las causas del "no".

116 Cfr. Le Monde, 2 de junio de 2005.

117 Cfr. El País, 2 de junio de 2005, p. 2.

118 En efecto, según constata Internacional Herald Tribune, (3 de junio de 2005, p. 3), en Francia existe una profunda animadversión por lo que todos, desde José Bové y Le Pen a Chirac y Laurent Fabius denominan ultraliberalismo, que viene a equivaler al modelo anglosajón. Este rechazo no es sino una nueva variante de un tema tan antiguo como la $V$ República misma: la lucha entre la dominación angloamericana y la necesidad de presentar a Francia como una alternativa humanista a esa dominación.

119 Según Irwin M. Stelzer, del Hudson Institute, para conseguir el triple objetivo de crear empleo, subir la tasa del crecimiento y recuperar la confianza del resto de miembros de la Unión, Francia deberá reducir la fiscalidad empresarial y favorecer la flexibilidad del mercado de trabajo (cfr. "Economie», en Le Monde, 1 de junio de 2005, p. I).

120 Seguirá conservando, sin embargo, su cargo de presidente de la UMP, lo que ha suscitado vivas críticas de otros grupos por violar las reglas que prohíben el cúmulo de cargos. EI PS denuncia una notoria incompatibilidad democrática entre el cargo de jefe de un partido y el de Ministro del Interior (cfr. Le Figaro, 2 de junio de 2005).

(C) UNED. Revista de Derecho Político 
6.6. Durante la campaña los políticos defensores del Tratado, más informados por haber participado más en el proceso de elaboración de la Constitución (desde Raffarin o Chirac a Hollande o Jospin), han dado la impresión de seguir en los grandes temas y no han conseguido descender a la población ${ }^{121}$. Esta falta de pragmatismo ha sido aprovechada por el campo del "no", que ha sabido utilizar temas de gran calado social, aunque no siempre con fundamento, lo que ha obligado al campo del "sí" a actuar a la defensiva, en vez de poder exponer sus propios argumentos ${ }^{122}$.

6.7. Los antiguos dinosaurios, los jubilados de la política o los que en la actualidad están un poco al margen de implicaciones políticas, como Beretrand Delanoë, Lionel Jospin, Jack Lang o Ségotene Royal, Simone Veil o Jacques Delors parecen haber sido más dignos de crédito en esta campaña que líderes oficiales, como el binomio Chirac-Raffarin, François Hollande o incluso Laurent Fabius. En la mayoría sólo Sarkozy parece haberse salvado algo de la impopularidad que rodea a la UMP. En efecto, el mayor grado de impopularidad parece haberlo obtenido la cúpula ejecutiva ${ }^{123}$.

6.8. Se aprecia una clara utilización demagógica de los temas de la campaña. La principal causa del rechazo de la Constitución ha sido, sin duda, el elevado desempleo ${ }^{124}$. Se ha culpado al liberalismo de los males nacionales, mientras que todos los expertos coinciden en afirmar que la solución a los mismos pasa por la liberalización de la economía y el mercado de trabajo. Además la parte criticada ha sido la parte III, cuando ésta no supone ningún cambio con la situación anterior pues es una recopilación de textos ya aprobados ${ }^{125}$ y sobre los que los Estados no pueden pronunciarse en una consulta de este tipo. Esta circuns-

121 En efecto, como indica Casanova (cfr. Le Monde, 1 de abril de 2005, "Analyse»), de poco sirve explicar al electorado que provocará un crecimiento de la producción per-capita, pues en el juego del crecimiento, si todo el mundo gana de media, hay algunos que ganan de verdad y otros que pierden o que ganan menos. $A$ estos últimos no se les puede ir con argumentos estadísticos.

122 Al final de la campaña, cuando los chiraquíes reflexionen sobre sus errores, reconocerán el haber carecido de una línea directriz y el "haberse pasado el tiempo corriendo detrás del no" (opinión de Sarkozy publicada en Le Monde, 27 de mayo de 2005, p. 8).

123 Sondeo TNS-Sofres-Unilog para Le Monde, RTL y LCl (cfr. Le Monde, 18 de mayo de 2005, p. 6).

124 Un sondeo TNS-Sofres, realizado tras el rechazo de la constitución indica que esta es la preocupación principal para un $52 \%$ de la población.

125 Por poner un ejemplo, el artículo 210 de la Constitución viene a decir lo mismo que el artículo 137 del Tratado de Niza. 
tancia en principio inamovible, ha impedido que se aprobaran las partes I y II, que sí suponen una innovación política importante.

Chirac tampoco ha escapado a la demagogia y al caer en la tentación de agitar él también el fantasma del liberalismo, ha caído en el mismo error en el que cayó con el tema de la seguridad ciudadana en los comicios de 2007, pues ha dado más argumentos a sus contrincantes Fabius, Le Pen y Villiers.

6.9. En efecto, en esta sesgada utilización que se ha hecho del tema del liberalismo subyacen intereses claramente partidarios y electoralistas, no sólo en el lado de Chirac, sino también en de Fabius. Separándose de la línea oficial del PS, el número dos del PS y el ex dirigente Emmanuelli han conseguido dividir a la izquierda con el pretexto de "hacer oposición». Una vez rechazado el Tratado, han conseguido plantear la tesis de que el rechazo mayoritario del electorado socialista a la Constitución Europea demuestra la existencia de un desfase entre éste y sus representantes actuales ${ }^{126}$, lo que exige la celebración a corto plazo de elecciones internas, en las que intentarán presentarse como la alternativa más creíble a la dirección actual. La dirección del partido se ha visto así obligada a adelantar estos comicios internos, inicialmente previstos para la primavera de 2006, a noviembre de $2005^{127}$.

6.10. Los grandes beneficiarios de esta consulta han sido, en Francia, Le Pen, que ahora se encuentra mejor situado de cara la las presidenciales (si bien, tendrá, posiblemente, que competir duramente con Villiers, que podría haber captado a una parte de su electorado) y Laurent Fabius, del que todo indica que será un candidato a las presidenciales independientemente de que logre o no imponer su liderazgo en las elecciones internas del PS que se celebrarán, de forma adelantada, en otoño, lo que por el momento parece poco probable.

6.11. Fuera de Francia, el beneficiado por el resultado de la consulta ha sido Reino Unido que, tras la suspensión de la consulta referendaria, con un presidente francés y un canciller alemán claramente debilitados, y con el respaldo que le proporciona su reciente reelección y su próxima presidencia de la UN en el segundo trimestre de 2005, intentará imponer el modelo anglosajón de un gran mercado. Ya ha de-

126 Emmanuelli ha declarado "somos la izquierda útil», la que acepta confrontarse con la realidad (cfr. Le Monde, 18 de junio de 2005).

127 En el momento de concluir este artículo, en el cierre de la Universidad de Verano de los socialistas celebrada en la Rochelle el 28 de agosto, Holland ha seguido manteniendo la unidad, si bien ésta parece ficticia, pues los sectores más críticos estaban ausentes o no se manifestaron (cfr. El Mundo, 29 de agosto de 2005, p. 20). 
clarado su voluntad de erigirse en reformador del modelo social europeo frente a los que sostienen una Europa "anclada en el pasado" ${ }^{128} \mathrm{y}$, por el momento, aparte de suprimir unilateralmente la consulta británica sobre la Constitución, ha conseguido bloquear los presupuestos 2007-2013, sobre los que no ha podido llegar a un acuerdo la cumbre de jefes de Estado y de gobierno de mediados de junio, organizada bajo la presidencia luxemburguesa. En ésta Gran Bretaña ha sostenido que considera excesivas las ayudas comunitarias, en especial en materia agrícola, de las que Francia se beneficia de modo principal, y que sigue sin querer renunciar al Ilamado "cheque británico", que Tatcher consiguió para su país tras duras negociaciones en 1984, durante la época en la que era conocida como "la dama de hierro".

6.12. Sin embargo, el beneficiario por excelencia de la crisis que se ha producido tras el doble rechazo, en Francia y Holanda, de la Constitución Europea ha sido, sin duda, Estados Unidos, que, con el inmovilismo europeo (el Tratado de Niza, que seguirá aplicándose exige la unanimidad para un amplísimo elenco de acuerdos), no tendrá que preocuparse, por el momento, de ver su liderazgo mundial cuestionado.

6.13. Precisamente las circunstancias expuestas en los dos puntos anteriores pueden hacer que la maniobra de Fabius y Emmanuelli consistente en dividir al PS para imponer su liderazgo se vuelva contra ellos, pues al ex numero dos del PS (él y sus seguidores han sido destituidos por Holland de la dirección del partido tras el referéndum) se le empieza a acusar de haber echado a Francia en los brazos de Blair. En el Partido Socialista es escaso el número de dirigentes que confían en Fabius $^{129}$.

6.14. En Francia el gran perdedor político del escrutinio ha sido, sin duda, Jacques Chirac. Al convocar el referéndum, en cuyo resultado se comprometió públicamente, pretendía una ventaja política. Ahora que ha fracasado, se niega a vincular su suerte a la del Tratado y sin duda se escudará en el argumento de que nadie puede reprocharle haber consultado al pueblo francés en un tema de tanta trascendencia para sus destinos como el dar una Constitución a la Europa a la que pertenecen. Este argumento le librará de la necesidad de dimitir pero no, muy posiblemente, de no resultar elegido en 2007 , dado que le será muy difícil remontar su imagen ante la opinión pública tras haber

128 Cfr. Le Figaro, 20 de junio de 2005 y Le Monde, 18 y 24 de junio de 2005.

129 Sólo un $12 \%$, en el mismo nivel que Hollande. Lionel Jospin es el mejor situado (un $31 \%$ ), mientras que a Strauss-Khan y Jack Lang se les atribuye sólo un $19 \%$ y un $13 \%$ respectivamente (cfr. Le Figaro, 7 de junio de 2005). 
alcanzado la mayor cota de impopularidad en la historia de la Repúbli$\mathrm{ca}^{130}$. Las encuestas parecen indicar que, de ganar la UMP en 2007, deberá ser de la mano de Sarkozy, favorito indiscutible de las encuestas.

6.15. Sin embargo, para ver vislumbrar la posibilidad de una alternancia en 2007 de la mano del PS (si sigue la tendencia iniciada en las pasadas elecciones regionales y europeas) será necesario que la izquierda plural consiga unirse y lanzar un proyecto creíble para 2007 (la crisis interna que atraviesa sin duda le restará energías de cara a esta cita electoral). El mejor dotado para reunir a la izquierda, así como el mejor situado para las presidenciales de 2007 parece ser Dominique Strauss-Khan, antiguo ministro de finanzas, que dos meses después del referendum ha anunciado que los militantes deberán de elegir entre su candidatura y la de Fabius ${ }^{131}$.

6.16. La extrema izquierda, unida por el "no" durante la campaña del referéndum, está lejos de llevar a cabo una batalla unitaria durante los próximos comicios de 2007, pues mientras Buffet, la líder del PCF, es partidaria de acuerdos electorales con el PS, Besancenot (LCR) estima que existen dos izquierdas incompatibles: la una, socio-liberal, encarnada por el PS y, la otra, de izquierda radical, encarnada por .... i esa es la cuestión! ${ }^{132}$

6.17. El debate sobre la Constitución Europea en Francia ha puesto de manifiesto la existencia de un conflicto de intereses entre los antiguos y nuevos países de la UE. Los países de la vieja Europa son más reacios a la liberalización de los servicios (de ahí el temor a la directiva Bolkenstein y a las deslocalizaciones), mientras que los nuevos países, antiguos países soviéticos, tienen miedo a las reglamentaciones excesivas y son partidarios de una mayor liberalización. Tras el rechazo de Francia y Holanda al Tratado se ha marcado más esta línea divisoria entre los países con un crecimiento más lento y más proteccionistas (principalmente Francia y Alemania), por un lado, y los más reformistas (Gran Bretaña y los países del Este), por otro ${ }^{133}$. Además estos países no entienden cómo Francia, que ha estado en el origen de todos los proyectos de construcción Europea, dé su negativa ahora a un refe-

130 Alrededor del $70 \%$ de los ciudadanos están, según los sondeos, descontentos con la gestión de Chirac (cfr. Le Figaro, 8 de junio de 2002 y Le Monde, 21 de junio de 2005). Pese a que, pasado más de un mes del referéndum, la gestión de Villepin ha sido bien acogida, pues éste ha subido 9 puntos en el barómetro Sofres (cfr Le Figaro, 6 de agosto de 2005, pp. 12-13).

131 Cfr. Le Figaro, 29 de agosto de 2005.

132 Cfr. Le Figaro, 29 de agosto de 2005, p. 5.

${ }^{133}$ Cfr. Internacional Herald Tribune, 3 de junio de 2005, p. 1. 
réndum que es, en cierto modo, una ratificación sobre la ampliación de Europa, y ven en esta negativa un egoísmo de "cortas miras»" ${ }^{134}$.

6.18. El 1 de junio también ha sido rechazada la Constitución Europea en el referéndum celebrado en Holanda ${ }^{135}$. Con este doble rechazo se ha abierto para Europa un período de incertidumbre, agravado por la posterior falta de acuerdo sobre los presupuestos de 2007-2013 y por la suspensión por Gran Bretaña de su referéndum interno. Contrariamente a lo aducido por los defensores de la Constitución sobre la ausencia de un plan "B", tras el doble rechazo de Francia y Holanda, en el seno de la Unión se han esbozado un número importante de planes alternativos para salir de la crisis abierta. Sin embargo, la gravedad de ésta sólo se ha visto mitigada por la ratificación del Tratado por Luxemburgo en el referéndum celebrado el 10 de julio ${ }^{136}$, aprobación a la que sin duda ha contribuido el "buen hacer» de su primer ministro Jean-Claude Juncker, presidente saliente de la Unión, que sacando partido de la extraordinaria confianza de la que goza (un 88\%), aseguró dimitir en caso de que ganase el "no» ${ }^{137}$.

\section{VALORACIÓN JURÍDICO-POLÍTICA}

\subsection{Un cambio en el sentido del referéndum}

Hay dos temas, a nuestro juicio, dignos de mencionarse sobre el hecho de que Chirac haya recurrido a este referéndum como vía de ratificación de la reforma constitucional que se aprobó en el Parlamento.

En primer lugar, está el hecho de que, gozando de mayoría, no haya optado, como le habilita el apartado tercero del artículo 89, por la aprobación parlamentaria, cuando la tenía garantizada, pues el Parlamento ya había aprobado el proyecto de reforma, por masiva mayoría, el 28 de febrero.

Parte de la doctrina ha afirmado que los cambios que la Constitución de 1958 habría sufrido como consecuencia de la aprobación del Tratado sobre la Constitución Europea no justificaban por sí solos esta

134 Cfr. Le Figaro, 10 de junio de 2005, p. 14.

135 El porcentaje de votos negativos ha sido de un 62\% (cfr. Le Monde, 2 de junio de 2005). Aquí el tema principal del debate no ha sido tanto el desempleo, como la soberanía.

136 Por 56,52\% de los votos, contra 43,48\% (cfr. Le Figaro, 11 de julio de 2005).

137 Cfr. Le Figaro, 9 de julio de 2005. 
forma de consulta. Un referéndum, al igual que unos comicios, siempre implica riesgos y Chirac no ha logrado imponer su criterio de una campaña corta ${ }^{138}$. Además al actual jefe del Estado siempre le ha fallado el olfato político en este tipo de maniobras a gran escala. Un buen ejemplo fue la disolución de la Asamblea en 1997, que en lugar de acabar con la cohabitación, que era lo que se pretendía, creó una nueva ${ }^{139}$.

Las razones para no optar, como otros países, por la cómoda aprobación parlamentaria pueden haber sido varias. La oficial, la que él mismo ha apuntado, es la de haber querido dar participación al pueblo francés en un tema como el del Tratado de la Unión, de considerable interés ciudadano, una vez conseguida la aprobación de las asambleas ${ }^{140}$; otra, quizás, relacionada con la primera (partiendo de unas primeras estimaciones positivas de la reacción del electorado y animado por el amplio respaldo parlamentario), la de haber intentado, al estilo de los referendos de De Gaulle ${ }^{141}$, revalidar la confianza depositada en él tras el seísmo de las presidenciales de 2002 y disipar así cualquier posible duda sobre "voto forzado a Chirac para evitar a Le Pen", -recordemos que éste se colocó directamente frente a él en la segunda vuelta de las elecciones, tras eliminar al candidato socialista Jospin-. Otra, más retorcida, pero muy habitual en política, puede haber sido la de querer dividir a la izquierda electoral y, de paso, asegurar para la UMP el resultado de las presidenciales de 2007, pero no sin antes ganarse el voto de la izquierda parlamentaria y de los Verdes para su proyecto de revisión. Confirma este hecho el haber vinculado al mismo proyecto de revisión la polémica Carta sobre Medioambiente, que los socialistas se han visto obligados a aprobar, para no pasar por antieuropeos. De este modo Chirac puede haber pretendido alejar a parte del electorado de izquierdas de sus representantes en la Asamblea, a los que pueden acusar de "hacer el juego a Chirac", lo que ha conseguido, pero a un costoso precio para él y la UMP, pues ha fallado en la tarea principal, la de conseguir la ratificación.

138 Cfr. Le Monde, 05.03.2005, p. 1

139 Otro gran error fue, como hemos dicho, enarbolar, la bandera de la seguridad durante los comicios de 2002, con lo que en realidad consiguió engrosar las listas de los votantes al Frente Nacional.

140 En la entrevista que durante la campaña mantendrá con los jóvenes de la Sorbonne declara: "...Naturalmente, lo fácil habría sido ir por la vía parlamentaria. Cada uno hace lo que cree que debe hacer o lo que las instituciones le permiten..." (cfr. Le Monde, 16 de abril de 2005, p. 9).

141 En la misma entrevista sostiene más adelante: "...¿por qué el referéndum?...Pienso que esta forma de consulta debería estar en la costumbre francesa, ser cada vez más un modo de decisión..." 
En segundo lugar, se constata, sin embargo, que Chirac no ha asumido la consecuencia lógica que de Gaulle extraía del rechazo popular al referéndum: la dimisión. Este hecho no hace sino confirmar un cambio en el sentido del referéndum respecto del que tenía a comienzos de la $\mathrm{V}$ República. Por mucho que la situación socio-política por la que pasa Francia haya convertido esta consulta en una suerte de comicios nacionales, la resonancia plebiscitaria del referéndum ya no es tan grande como antaño. La negativa al Tratado sobre la Constitución Europea no se ha interpretado - 0 no ha querido interpretarse-como una retirada directa de la confianza del pueblo a su Jefe del Estado. $\mathrm{Na}$ die ha discutido la forma de la ratificación - tampoco se hizo en Maastricht- La escogida parece lógica, al tratarse de aprobar un texto de naturaleza constitucional que crea en la Unión Europea una presidencia estable y fija reglas para la adopción de normas, de aplicación en los Estados miembros. Paradójicamente, esta forma de entender el referéndum resulta más democrática, pues la consulta ya no se usa como arma para "chantajear" al electorado, ni como sustituto de la disolución. Esto requería una enorme concentración de poder y Chirac carece de ella.

\subsection{La cohabitación, mejor funcionamiento de las instituciones}

Después de tres años de funcionamiento presidencialista de las instituciones se puede hacer una pequeña valoración de los avances políticos que la coincidencia de mayorías ha supuesto para Francia respecto de la época inmediatamente anterior de cohabitación o diarquía institucional, que acabó tras los dobles comicios de 2002.

Recordemos que en 2002 fue tarea principal del Ejecutivo bicéfalo de la cohabitación acabar con ésta, para lo que se ideó la concomitancia de la elección presidencial con la de la Asamblea y se invirtió el calendario electoral para que la primera, la elección presidencial, se convirtiera en el momento fuerte de la vida política. Se reprochaba a la cohabitación que paralizaba las instituciones, que frenaba el impulso político, pues ambas cabezas del ejecutivo se dedicaban más a aprovechar y conservar las facultades que la Constitución les confería que a hacer la tarea que les era propia.

La reforma de 2000 no haría sino asegurar que en lo sucesivo siguiera dándose esa coincidencia de mayorías presidencial y parlamentaria, pero no, sin embargo, para que cada una de las cabezas del ejecutivo hiciera la tarea que la Constitución le confiere, sino para que el Jefe del Estado continuase siendo el jefe absoluto del Estado y su Pri- 
mer Ministro, jefe del Gobierno, un simple lacayo, es decir, para que el Jefe del Estado gobernara y el Primer Ministro obedeciera sin chistar. En efecto, la práctica presidencialista ha mostrado que los poderes del Presidente de la República pueden sobrepasar ampliamente los que le concede la Constitución cuando la mayoría que lo ha llevado a la Presidencia coincide con la de la Asamblea, porque entonces él es el auténtico jefe de ambas.

Ambos funcionamientos, el parlamentario y el presidencialista son posibles dentro de la Constitución. Michel Debré, el padre de la Constitución de 1958, fue consciente de ello ${ }^{142}$. Hasta 1986, año en el que se inició la primera diarquía, la práctica presidencialista descansó en la base jurídica que le proporcionaba el artículo 8 tras la reforma de $1962^{143}$ y en una situación política meramente conyuntural: la existencia en la asamblea de una mayoría estable favorable al presidente.

Sin embargo la concepción presidencialista de la Constitución dejaba una brecha evidente: la irresponsabilidad del Jefe del Estado, consagrada en el artículo $68^{144}$, no se correspondía con su enorme dosis de poder. De Gaulle paliaría esta evidente brecha jurídica comprometiendo

142 Este mismo expresaría la formula que ilustra este doble funcionamiento de la Constitución de 1958: Cuando la mayoría presidencial se corresponde con la mayoría parlamentaria el Presidente hace lo que quiere. Cuando la mayoría parlamentaria no se corresponde con la mayoría presidencial, es la cohabitación, pero ahora el Primer Ministro hace lo que quiere (entrevista con el Quotidien de París de 30 de noviembre de 1989, en ZARKA, Jean-Claude, Fonction présidentielle et problématique majorité présidentielle/mayorité parlamentaire sous la Cinquième République (1986-1992), París, Librairie Générale de Droit et de Jurisprudence, 1992 (p. 13).

${ }_{143}$ Con la revisión constitucional de 1962, tras la que el Presidente es elegido por medio de sufragio universal directo, de Gaulle vendrá a legitimar erróneamente esta práctica, consciente de que sus sucesores en la Presidencia no contarán con su misma legitimidad histórica. Sin embargo, coincidimos con Philippe ARDANT en que la revisión de 1962 no alarga la lista de poderes presidenciales, sino que tan sólo contribuye a alejar la elección presidencial de las intrigas partidarias (cfr. ARDANT, Philippe. Institutions politiques et droit constitutionnel, 11e édition, Librairie générale de droit et de jurisprudence, E.J.A., París, 1999, pp. 443 y 460). Según el mismo autor, la elección mediante sufragio universal directo legitima la autoridad del Presidente como institución, porque gracias a la misma él cuenta con la confianza explícita de la nación, pero no por ello legitima una práctica política que se sale de la letra de la Constitución. En este sentido cfr. ARDANT Philippe, "L'article 5 et la fonction présidentielle»(en VV.AA, "Le Président", en Pouvoirs, n. ${ }^{\circ} 41$, París, Presses Universitaires de France, 1987, p.49).

144 Artículo 68 de la Constitución francesa: «El Presidente de la República no será responsable de los actos realizados en el ejercicio de sus funciones sino en el caso de alta traición. No podrá ser acusado sino por las dos asambleas, pronunciándose 
su responsabilidad al resultado de los referendos que organizaba, lo que le valió su dimisión en 1969.

Ahora, casi cincuenta años después de la promulgación de la Constitución, constatamos que las consultas al pueblo ya no se utilizan como baremo de la gestión presidencial, a menos que su resultado sea positivo. El Jefe del Estado se limita a culpar a su equipo de Gobierno, intentando pasar por alto que cuando el Presidente es el jefe supremo del ejecutivo el Gobierno no gobierna, sino que se limita a aceptar la responsabilidad por actos de gobierno en los que sólo él decide. El equipo de gobierno está debilitado, lo que redunda, a su vez, en el debilitamiento de la institución presidencial que, no obligada a rendir cuentas, se acomoda y ralentiza, al tiempo que dedica la mayor parte de sus energías a asegurarse la reelección. El referéndum del 29 de mayo es también una buena prueba de esta afirmación.

Lo expuesto es sólo otro apoyo al argumento, sostenido por buena parte de la doctrina, de que es durante la diarquía cuando la coincidencia entre texto y praxis o, lo que es lo mismo, entre el elemento jurídico y político del sistema, es más completa, y que, por consiguiente, es también durante este período cuando asistimos a un funcionamiento del régimen más acorde con las instituciones. Sólo en diarquía la responsabilidad del Gobierno puede ser cuestionada por la Asamblea, que deja de cumplir una función meramente notarial para hacer la tarea que le es propia, controlar a aquél. Y sólo en diarquía el Presidente realiza la función eminentemente simbólica que le corresponde, al lado de otros poderes nada desdeñables (como la disolución), pero de los que no puede disponer a su antojo.

\subsection{La elección presidencial sigue siendo, en opinión de los principales partidos, el momento fuerte de política}

Pese a lo expuesto en el punto VI.2., en la mente de muchos dirigentes políticos sigue primando la idea de que la vida política del país debe de seguir girando en torno a la elección presidencial. También una buena parte de los líderes del Partido Socialista, tras haber criticado durante mucho tiempo la elección presidencial por sufragio universal, acusándola de monopolizar el debate sobre las instituciones y de re-

éstas por un voto idéntico en votación pública y por la mayoría absoluta de los miembros que las componen; será juzgado por el Tribunal Supremo de Justicia (traducción recogida de Álvarez VÉlez, M. ${ }^{a}$ Isabel y Alcon YustAS, M. ${ }^{a}$ Fuencisla, Las Constituciones de los Quince Estados de la Unión Europea, op. cit.). 
ducir la elección democrática a una elección de personas más que de ideas políticas ${ }^{145}$, parece haberse acomodado a la ambivalencia de las instituciones ${ }^{146}$. Los socialistas han lanzado sus propuestas de reforma de la Constitución de cara al congreso que tendrá lugar en noviembre; sin embargo en muchos aún parece pesar la sombra del fantasma de la IV República. En efecto, si bien en el seno del partido existe un consenso sobre el debilitamiento de las instituciones y la necesidad de reforzar los poderes de la Asamblea Nacional, existe un claro desacuerdo entre los que defienden un régimen presidencial y los que sostienen la necesidad de que el régimen de la $\mathrm{V}$ República funcione como parlamentario. François Holland espera que este nuevo debate reemplace a la división surgida dentro del partido durante la campaña del referéndum y confía en captar hacia la opción presidencialista a los militantes del NPS (Nuevo Partido Socialista) de Arnaud Montebourg y Vincent Peillon, que propugnan una VI República y que, desde hace tiempo, han hecho de la instauración en Francia de un régimen parlamentario su caballo de batalla ${ }^{147}$.

145 Mitterrand dijo "La V República era peligrosa antes de mí y lo será después» (cfr. Le Figaro, 25 de junio de 2005).

146 No así, por ejemplo, Emmanuelli, que preguntado después del 29 de mayo sobre si se embaucará en las próximas elecciones ha contestado «dejad de reducir la política a la elección presidencial» (cfr. idem, id.).

147 La moción Del NPS obtuvo casl el 17\% de los votos en 2003 durante el congreso de Dijon. Cfr. Le Figaro, 25 de junio de 2005. 